\title{
1 A giant leap in sequence space reveals the intracellular complexities of evolving a new
}

\section{2 function}

3 Kelsi R. Hall ${ }^{1,2}$, Katherine J. Robins ${ }^{1,3}$, Michelle H. Rich ${ }^{1,4}$, Mark J. Calcott ${ }^{1,2}$, Janine N.

4 Copp $^{1,5}$, Elsie M. Williams ${ }^{1,2}$, Rory F. Little ${ }^{1,6}$, Ralf Schwörer ${ }^{2,7}$, Gary B. Evans ${ }^{2,7}$, Wayne M.

5 Patrick $^{1,2}$, David F. Ackerley ${ }^{1,2, *}$.

$6{ }^{1}$ School of Biological Sciences, Victoria University of Wellington, Wellington 6012, New

7 Zealand.

$8{ }^{2}$ Centre for Biodiscovery, Victoria University of Wellington, Wellington 6012, New

9 Zealand.

$10{ }^{3}$ Current address: The University of Manchester, Manchester M13 9PL, United Kingdom.

$11{ }^{4}$ Current address: BiOrbic, SFI Bioeconomy Research Centre, University College Dublin,

12 Belfield, Dublin, Ireland.

$13{ }^{5}$ Current address: Michael Smith Laboratories, University of British Columbia, Vancouver, 14 BC V6T 1Z4, Canada.

$15{ }^{6}$ Current address: Leibniz Institute for Natural Product Research and Infection Biology, Hans 16 Knöll Institute, 07745 Jena, Germany.

$17{ }^{7}$ Ferrier Institute, Victoria University of Wellington, Lower Hutt 5010, New Zealand

$18 *$ Corresponding author: david.ackerley@vuw.ac.nz

\section{Abstract}

21 Selection for a promiscuous enzyme activity provides substantial opportunity for competition between endogenous and new substrates to influence the evolutionary trajectory, an aspect that has generally been overlooked in laboratory directed evolution studies. We evolved the Escherichia coli nitro/quinone reductase NfsA to detoxify chloramphenicol by randomising eight active site residues simultaneously and interrogating $\sim 250,000,000$ reconfigured NfsA variants. Analysis of every possible evolutionary intermediate of the two best chloramphenicol reductases revealed complex epistatic interactions that restrict each

28 hypothetical trajectory. In both cases, improved chloramphenicol detoxification was only possible after one essential substitution had eliminated activity with endogenous quinone substrates. Unlike the predominantly weak trade-offs seen in previous experimental studies, this substrate incompatibility suggests endogenous metabolites have considerable potential to shape evolutionary outcomes. Unselected prodrug-converting activities were mostly unaffected, which emphasises the importance of negative selection to effect enzyme 
specialisation, and offers an application for the evolved genes as dual-purpose selectable/counter-selectable markers.

\section{Introduction}

Many (if not all) enzymes are promiscuous, meaning that in addition to their primary biological role(s) they can catalyse minor side reactions that have no apparent physiological relevance, either because they are too inefficient or because the substrate is not naturally encountered (Copley, 2015). From an evolutionary perspective, promiscuity can play an important role in contingency, i.e. providing a reservoir of potential functions that a cell can tap in response to changing circumstances (O'Brien and Herschlag, 1999; Copley, 2015). As demonstrated by the emergence of resistance to xenobiotic pollutants or clinical antibiotics (O'Brien and Herschlag, 1999; Hall, 2004; Ramos et al., 2005; Copley, 2009; Khersonsky and Tawfik, 2010), a strong selection pressure can cause latent promiscuous activities to be rapidly amplified to physiologically relevant levels (Newton et al., 2015).

Catalytic transitions to an alternate substrate have been modelled experimentally using iterative rounds of random mutagenesis (e.g., error-prone PCR), a powerful directed evolution strategy that enables adaptive landscapes to be explored under defined laboratory conditions (Kaltenbach et al., 2015; Kaltenbach et al., 2016). These laboratory evolution studies have indicated that selection for substantial increases in a promiscuous activity typically results in only weak trade-offs against the native activity; and therefore, the transition from one primary function to another tends to progress via generalist enzyme intermediates (Kaltenbach et al., 2016). Two leading teams have offered contrasting hypotheses to explain this phenomenon. In 2005, Tawfik and co-workers proposed that enzymes possess an innate 'robustness' and stability that buffers them against the potentially detrimental effects of novel mutations, coupled with a 'plasticity' that can amplify promiscuous functions with relatively few mutations (Aharoni et al., 2005). More recently, Tokuriki and co-workers demonstrated that a robust native activity is not a prerequisite for weak trade-offs, and suggested that their predominance in the literature may instead be artefactual; a consequence of laboratory evolution studies being highly biased toward strong selection for a new function without any selection against the native activity (Kaltenbach et $a l ., 2016)$. They argue that it is unclear how specialisation can occur in this manner, and that in nature, selection might frequently exist to erode the original function. By way of example, 
they offer a scenario where the native and new substrate compete for the same active site (Kaltenbach et al., 2016).

In addition to their exclusive emphasis on positive selection, we note that these pioneering previous studies were also heavily biased toward heterologous enzyme expression and/or a transition in activity from one exogenously applied substrate to another (Kaltenbach et al., 2016). Thus, there has been little consideration of how the native substrate might influence the evolutionary trajectory. We were therefore motivated to study evolution of a promiscuous function within the native host environment, and were particularly interested to focus on the key catalytic changes driving the transition. Recognising that the stochastic nature of iterative random mutagenesis is unlikely to yield the most efficient pathway to an evolved outcome, we sought to implement simultaneous mass-mutagenesis on a massive scale that would allow us to retrospectively assess all possible intermediates of our top variants, and infer the most plausible evolutionary trajectories. We were able to achieve both these goals by employing the Escherichia coli nitro/quinone reductase NfsA as a new model system that offers several key advantages. NfsA is a member of a large bacterial superfamily comprising highly promiscuous FMN-dependent oxidoreductases that accept electrons from NAD(P)H and transfer them to a diverse range of substrates (Williams et al., 2015; Akiva et al., 2017). Expression of $n f s A$ is governed by the soxRS regulon, and NfsA is thought to guard against oxidative stress through reduction of water-soluble quinones such as 1,4-benzoquinone (Liochev et al., 1999; Paterson et al., 2002; Copp et al., 2017). Although most efficient with quinone substrates, NfsA is also able to reduce a wide diversity of nitroaromatic compounds (Valiauga et al., 2017). This is generally believed to represent non-physiological substrate ambiguity, as there are relatively few nitroaromatic natural products, and in many cases nitroreduction yields a more toxic derivative (Winkler and Hertweck, 2007; Parry et al., 2011; Williams et al., 2015). An important exception is that nitro-reduction of chloramphenicol transforms this antibiotic to a product that is not discernibly toxic to bacteria (Yunis, 1988; Smith et al., 2007; Crofts et al., 2019). We have observed that over-expressed native NfsA confers only slight chloramphenicol protection to $E$. coli host cells, but reasoned that we could select for improved detoxification in an extremely high throughput manner by plating variant libraries on chloramphenicol-amended media. Because members of the bacterial nitroreductase superfamily appear to have unusually plastic active sites (Akiva et al., 2017), we considered that simultaneous mass-mutagenesis of up to eight active site residues should be possible. In effect, we aimed to strip NfsA of its engine, and then select for a superior 
101

102

103

104

105

106

107

108

109

110

111

112

113

114

115

116

117

118

119

120

121

122

123

124

125

126

127

128

129

130

131

132

133

configuration of parts assembled within the empty chassis. By leaping directly to a new fitness peak, we considered that we might arrive at synergistic combinations of substitutions that would be difficult to achieve by iterative random mutagenesis approaches.

\section{Results}

Design of an eight randomised codon $n f s$ gene library

We have previously conducted several different mutagenesis studies on $n f s A$, seeking to enhance activity with prodrugs and/or positron emission tomography (PET) imaging probes for cancer gene therapy applications (Williams, 2013; Copp et al., 2017; Rich, 2017), or to assess potential collateral sensitivities between niclosamide and the antibiotics metronidazole and nitrofurantoin (Copp et al., 2020). Based on this previous work we empirically identified eight active site residues (S41, L43, H215, T219, K222, S224, R225 and F227; Fig. 1A) as being individually mutable and having the potential to contribute to generically improved nitroreductase activity. We then designed a degenerate gene library to enable simultaneous randomisation of each residue. As complete randomisation of target codons (e.g., NNK degeneracy) would have yielded an impractically large library of $>10^{12}$ (32 $2^{8}$ or more) gene variants, we instead used a restricted set (Fig. 1B). The degenerate codon NDT was preferred at most sites, as this specifies 12 different amino acids that represent a balanced portfolio of small \& large, polar \& non-polar, aliphatic \& aromatic, and negatively \& positively charged side chains (Reetz et al., 2008). However, at positions 219 and 222, NDT codons did not include the native NfsA residue as an option, so the alternative degeneracies NHT (12 unique amino acids) and VNG (11 unique amino acids) were chosen as acceptably balanced alternatives (Fig. 1B). In total, our library represented 430 million possible gene combinations, collectively specifying 394 million different NfsA variants.

\section{Selection and characterisation of superior chloramphenicol-detoxifying $N f s$ A variants}

Following artificial synthesis and cloning, our library was used to transform E. coli 7NT cells (a strain in which endogenous nitroreductase genes had been deleted). We ultimately recovered a total of 398 million transformed colonies, a collection predicted by GLUE (Patrick et al., 2003) to represent 252 million different NfsA variants. Despite the drastic reconfiguration of their encoded active sites, a surprising $0.05 \%$ of the gene variants ( 200,000 clones) were more effective than wild type $n f s A$ (i.e., enabled colony formation on LB agar amended with $3 \mu \mathrm{M}$ chloramphenicol, the lowest concentration at which wild type 
$n f s A$ was unable to support host cell growth). This robust tolerance to active site randomisation confirmed that NfsA exhibits a substantial degree of active site plasticity.

We next plated the library on $\geq 45 \mu \mathrm{M}$ chloramphenicol, recovering a total of 365 colonies. Retransformation of the variant-encoding plasmids into fresh 7NT host cells to eliminate any selected chromosomal mutations, followed by validation of activities in liquid growth assays, then sequencing and elimination of duplicates, yielded 30 top variants that exhibited evidence of a conserved genetic response to the chloramphenicol selection. Particularly strong trends were observed at positions 41 and 219 (where the native serine or threonine was substituted by an aromatic residue in $\geq 26$ of the 30 cases), and at position 225 (100\% substitution of the native arginine by an uncharged or acidic residue) (Fig. 1C). Only at position 43 was the native or functionally similar residue frequently retained (16/30 cases). In $\mathrm{EC}_{50}$ assays, $7 \mathrm{NT}$ cells expressing these 30 variants demonstrated nearly 6- to 10-fold greater chloramphenicol tolerance than those expressing native $n f s A$ (Fig. 1D).

To evaluate the impact of the active site reconfiguration on catalytic activity, the top five chloramphenicol detoxifying NfsA variants were purified as His 6 -tagged proteins and evaluated in steady-state kinetics assays. We were surprised to discover that these variants exhibited only marginal (at most 2.2-fold) improvements in chloramphenicol $k_{c a t} / K_{M}$ over wild type NfsA (Table 1). However, in every case the variants were impaired in $k_{\text {cat }}$ (6-10 fold lower than NfsA) but greatly improved in $K_{M}$ (8-13 fold lower than NfsA). Thus, it appeared that the in vivo improvements in chloramphenicol detoxification were driven primarily by enhanced substrate affinity.

We previously observed a similar phenomenon when using an error prone PCR strategy to evolve NfsA for improved activation of the anti-cancer prodrug PR-104A, with all top variants exhibiting a lower $k_{\text {cat }}$ and lower $K_{M}$ for PR-104A, and none being significantly improved in $k_{\text {cat }} / K_{M}$ over the native enzyme (Copp et al., 2017). In that study, we postulated that the improved in vivo activities were a consequence of diminished competitive inhibition by native quinone substrates present in the E. coli cytoplasm; although the top variant was still active with 1,4-benzoquinone, we found its PR-104A reduction activity was less affected by addition of 1,4-benzoquinone to the reaction mix than was the case for wild type NfsA (Copp et al., 2017). We were therefore interested to discover whether our improved chloramphenicol-detoxifying variants from the present study were impaired in 1,4- 
bioRxiv preprint doi: https://doi.org/10.1101/2020.05.27.118489; this version posted May 30, 2020. The copyright holder for this preprint (which was not certified by peer review) is the author/funder, who has granted bioRxiv a license to display the preprint in perpetuity. It is made available under aCC-BY 4.0 International license.

168

169

170

171

benzoquinone reduction. In all cases, we found that 1,4-benzoquinone reduction was

unmeasurable (Table 1), suggesting that this activity had been actively and strongly selected against.

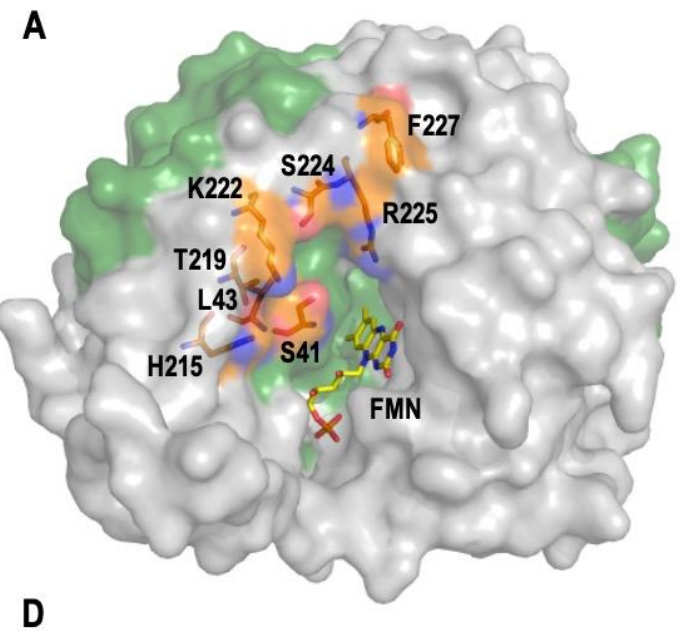

D

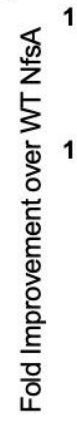

B

\begin{tabular}{ccc}
\hline $\begin{array}{c}\text { Degenerate } \\
\text { Codon }\end{array}$ & Amino Acids Encoded & $\begin{array}{c}\text { Position Codon } \\
\text { Employed At }\end{array}$ \\
\hline NDT & $\begin{array}{c}\text { Arg, Asn, Asp, Cys, Gly, His, } \\
\text { Ile, Leu, Phe, Ser, Tyr, Val }\end{array}$ & $\begin{array}{c}\text { S41, L43, H215, } \\
\text { S224, R225, F227 }\end{array}$ \\
NHT & $\begin{array}{l}\text { Ala, Asn, Asp, His, Ile, Leu, } \\
\text { Phe, Pro, Ser, Thr, Tyr, Val }\end{array}$ & T219 \\
& Ala, Arg, Arg, Gln, Glu, Gly, & K222 \\
VNG & Leu, Lys, Met, Pro, Thr, Val & \\
\hline
\end{tabular}

C

\begin{tabular}{|c|c|c|c|c|c|c|c|c|}
\hline & $\vec{y}$ & $\stackrel{m}{\Xi}$ & ? & స్ & $\underset{\mathbb{N}}{\mathbb{N}}$ & స్త్ర & $\underset{\mathbb{N}}{\mathbb{N}}$ & กิ \\
\hline Non-polar & 0 & 53 & 37 & 10 & 47 & 20 & 30 & 30 \\
\hline Polar & 0 & 43 & 17 & 0 & 20 & 20 & 60 & 7 \\
\hline Acidic & 0 & 0 & 23 & 0 & 13 & 7 & 7 & 27 \\
\hline Basic & 3 & 0 & 10 & 3 & 20 & 40 & 0 & 23 \\
\hline Aromatic & 97 & 3 & 13 & 87 & 0 & 13 & 3 & 13 \\
\hline
\end{tabular}

\section{NfsA_Ec Variant}

Figure 1: Creation, selection and characterisation of 30 top chloramphenicol detoxifying NfsA variants. (A) Structure of NfsA, based on PDB 1f5v. One monomer is shown is shown in grey and one monomer in green. The eight residues simultaneously targeted in NfsA (carbons in orange) and the FMN cofactor (carbons in yellow) are shown in stick form. For clarity, only one of the two FMN-binding active sites in the enzyme homodimer is portrayed. (B) Summary of the amino acid repertoire encoded by each degenerate codon. (C) Percentage of the five amino acid side-chain categories at each of the eight targeted positions for the top 30 chloramphenicol reducing variants. The property of the native amino acid at each position is boxed in red. (D) Fold-improvement in chloramphenicol $\mathrm{EC}_{50}$ values for $E$. coli $7 \mathrm{NT}$ strains expressing the top 30 chloramphenicol-detoxifying $n f s A$ variants over the native $n f s A$ control (far right). Data presented in Figures $1 D$ represents the average of at least four biological repeats \pm 1 S.D. 
bioRxiv preprint doi: https://doi org/10.1101/2020 05 27.118489; this version posted May 30, 2020. The copyright holder for this preprint (which was not certified by peer review) is the author/funder, who has granted bioRxiv a license to display the preprint in perpetuity. It is made available under aCC-BY 4.0 International license.

192

\begin{tabular}{rccccc}
\hline Variant & $\boldsymbol{k}_{\text {cat }}\left(\mathbf{s}^{-\mathbf{1}}\right)^{*}$ & $\boldsymbol{K}_{M}(\boldsymbol{\mu M})^{*}$ & $\begin{array}{c}\boldsymbol{k}_{\text {cat }} / \boldsymbol{K}_{M} \\
\left(\mathbf{M}^{-1} \cdot \mathbf{s}^{-1}\right)\end{array}$ & $\begin{array}{c}\text { Fold- } \\
\text { Improvement } \\
\text { over NfsA }\end{array}$ & $\begin{array}{c}\text { Turnover rate of } \\
\mathbf{1 0 0} \boldsymbol{\mu M} \\
\text { 1,4-benzoquinone } \\
\left(\mathbf{s}^{-1}\right)^{* *}\end{array}$ \\
\hline NfsA & $0.89 \pm 0.03$ & $1000 \pm 100$ & $860 \pm 90$ & 1.0 & $9.0 \pm 0.5$ \\
\hline 36_37 & $0.14 \pm 0.004$ & $130 \pm 20$ & $1100 \pm 200$ & 1.3 & N.D.*** \\
\hline 20_39 & $0.16 \pm 0.004$ & $80 \pm 10$ & $1900 \pm 200$ & 2.2 & N.D.*** \\
\hline 36_3 & $0.11 \pm 0.003$ & $130 \pm 10$ & $850 \pm 90$ & 1.0 & N.D.*** \\
\hline 37_4 & $0.09 \pm 0.004$ & $80 \pm 20$ & $1000 \pm 200$ & 1.2 & N.D.*** \\
\hline 19_22 & $0.13 \pm 0.003$ & $90 \pm 10$ & $1500 \pm 200$ & 1.7 & N.D.*** \\
\hline
\end{tabular}

Table 1: Kinetic parameters of chloramphenicol and 1,4-benzoquinone reduction for purified NfsA variants (the top five by in vivo $\mathbf{E C}_{50}$ ranking). Apparent $K_{M}$ and $k_{\text {cat }}$ at $250 \mu \mathrm{M}$ NADPH were calculated using Graphpad 8.0. Kinetic parameters could not be accurately determined for 1,4-benzoquinone for any of the selected variants; in an attempt to detect trace activities, the catalytic rate of 1,4-benzoquinone reduction was measured at a single high concentration of 1,4-benzoquinone $(100 \mu \mathrm{M})$, with reactions initiated by addition of $250 \mu \mathrm{M}$ NADPH. All reactions were measured in triplicate and errors are \pm 1 S.D. *Apparent $k_{c a t}$ and $K_{M}$ as determined at $250 \mu \mathrm{M}$ NADPH. **Measured rates following addition of $250 \mu \mathrm{M}$ NADPH. ***N.D. $=$ not detectable $\left(<0.1 \mathrm{~s}^{-1}\right)$.

\section{Recreating all possible evolutionary trajectories for the top chloramphenicol detoxifying} NfsA variants.

We next sought to probe the contributions to improved chloramphenicol detoxification and/or diminished 1,4-benzoquinone reduction made by key substitutions, or combinations thereof. The top two chloramphenicol detoxifying variants (36_37 and 20_39) each had seven substitutions at the eight targeted positions, with both containing the wild-type residue leucine at position 43 (36_37 = S41Y, H215C, T219Y, K222V, S224R, R225V, F227G; 20_39=S41Y, H215N, T219Y, K222R, S224Y, R225D, F227H; Figure 2A-C). Therefore, there are 126 possible intermediate forms $\left(2^{7}-2\right)$ between wild type NfsA and the evolved variant. Genes encoding the 126 intermediate forms for each variant were artificially synthesised, cloned and expressed in E. coli 7NT cells, and the chloramphenicol tolerance of the resulting strains assessed in $\mathrm{EC}_{50}$ growth assays. A Python script was generated to delineate all 5040 (7!) possible evolutionary trajectories and the output used to generate full network graphs (Figure 2D-E, Supplementary Figure S1). We then considered whether traditional stepwise directed evolution strategies, which require each substitution to directly improve the selected activity (e.g., across iterative rounds of error prone PCR), could have plausibly generated either of variants 36_37 or 20_39. For the purposes of this analysis we considered "improvement" to be a $>16 \%$ increase in chloramphenicol $\mathrm{EC}_{50}$ for each step, as 
bioRxiv preprint doi: https://doi.org/10.1101/2020.05.27.118489; this version posted May 30, 2020. The copyright holder for this preprint (which was not certified by peer review) is the author/funder, who has granted bioRxiv a license to display the preprint in perpetuity. It is made available under aCC-BY 4.0 International license.

this was the average error across all $\mathrm{EC}_{50}$ measurements. In neither case was there a clear path from NfsA to the final variant that involved exclusively upward steps in the hypothetical evolutionary trajectory (Figure 2D-F). Nevertheless, it was evident that the final two substitutions (H215C and K222V for variant 36_37, and K222R and S224Y for variant 20_39) did not contribute substantially to the overall chloramphenicol detoxifying activity of
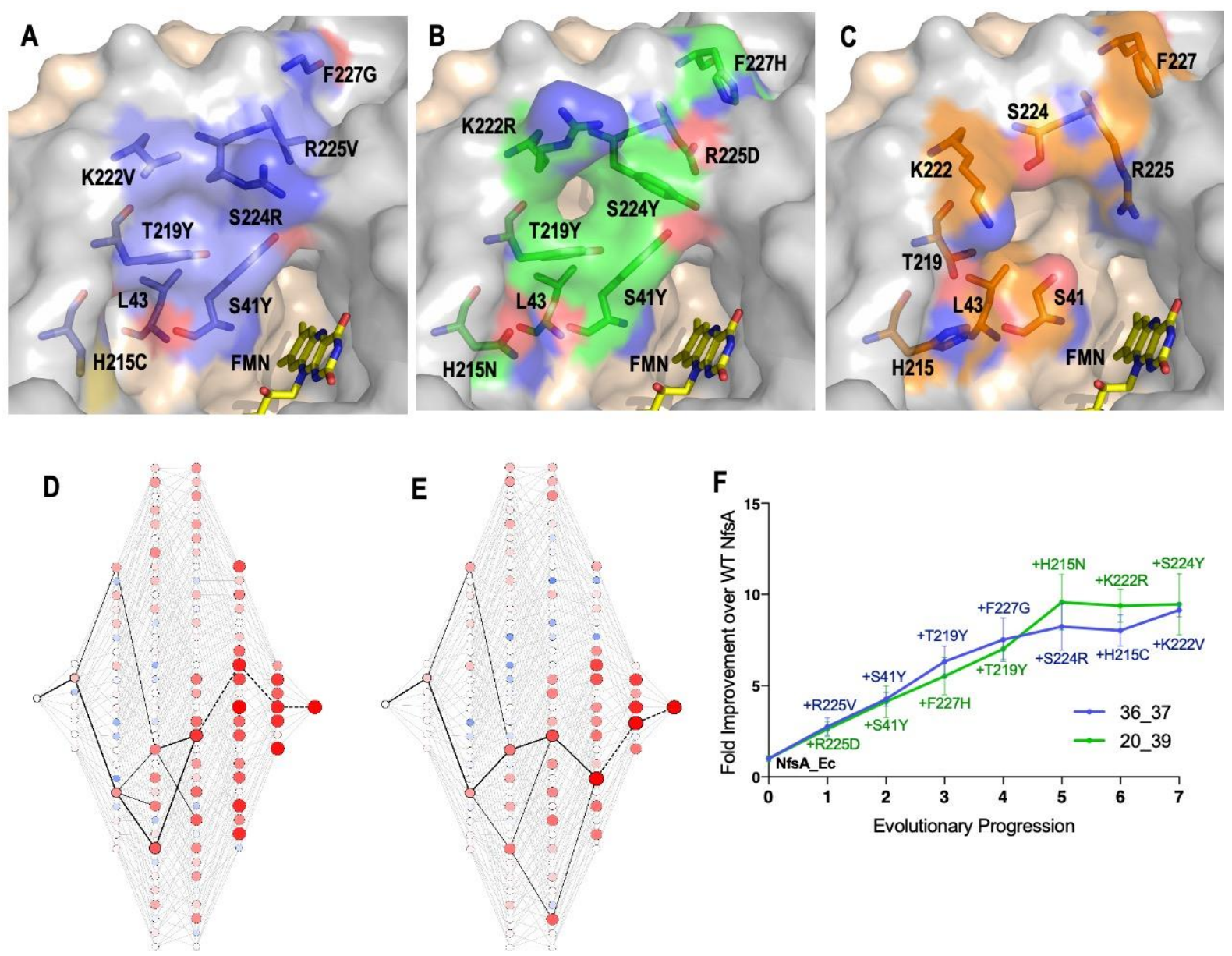

Figure 2: Recreating the hypothetical evolutionary trajectories of NfsA variants 36_37 and 20_39. (A-C) Residues in the active site of 36_37 (A, blue), 20_39 (B, green) and wild-type NfsA (C, orange); based on PDB 1f5v (Kobori et al., 2001). In each panel, one NfsA monomer is shaded grey and the other is pale pink. The orientation of the mutated residues in 36_37 and 20_39 was predicted using the mutagenesis wizard on PyMOL, which selected the most likely rotamer conformation based on the frequencies of occurrence in proteins while avoiding clashes with other residues. (D-E) All 5040 possible evolutionary trajectories of 36_37 (D) and 20_39 (E). Black lines represent primary paths in which each step resulted in $a \geq 16 \%$ increase in chloramphenicol detoxification. Thick black lines represent the most probable stepwise evolutionary trajectory as explained in Figure F. The colour and diameter of nodes corresponds to the fold-improvement in chloramphenicol detoxification over wild-type NfsA (blue/smaller = less active, red/larger = more active). A larger version of each image is provided in Supplementary Figure S1. (F) The most plausible stepwise evolutionary trajectory for each of variant 36_37 (blue) and variant 20_39 (green). To establish these, the substitution which resulted in the greatest improvement in chloramphenicol detoxification was selected at each point in the evolutionary progression. If no substitutions improved chloramphenicol detoxification, then the substitution was selected which resulted in the smallest decrease in activity (shown as a dotted black light in D-E). Data presented in 
bioRxiv preprint doi: https://doi.org/10.1101/2020.05.27.118489; this version posted May 30, 2020. The copyright holder for this preprint (which was not certified by peer review) is the author/funder, who has granted bioRxiv a license to display the preprint in perpetuity. It is made available under aCC-BY 4.0 International license.

242

243

244

245

246

247

248

249

250

251

252

253

254

255

256

257

258

259

260

261

262

263

264

265

266

267

268

269

270

271

272

273 each variant. Thus, we concluded that iterative evolutionary strategies could have plausibly generated NfsA variants exhibiting similar levels of chloramphenicol detoxifying activity to 36_37 and 20_39, but that there were very few accessible pathways for this (Figure 2D-E).

The dearth of accessible evolutionary pathways suggested extensive epistasis, a phenomenon that several teams have previously observed when evolving enzymes (Weinreich et al., 2005; Poelwijk et al., 2011; Kaltenbach and Tokuriki, 2014; Yang et al., 2019; Ben-David et al., 2020), where the fitness effects of certain substitutions only manifest when other substitutions have already been made. Most prominently, we noted that only one of the seven substitutions present in each of variants 36_37 and 20_39 significantly enhanced chloramphenicol detoxification when introduced on an individual basis (Figure 3A).

Although it was the same residue, R225, that was substituted in each case, the substituting residues possessed very different chemical properties (negatively charged aspartate in 20_39 versus non-polar valine in 36_37). This, together with the observation that none of our top 30 selected variants had retained a basic residue at position 225 (Figure 1C), indicated that it was essential for arginine 225 to be eliminated before the other active site substitutions could make a discernible contribution to improved chloramphenicol detoxification.
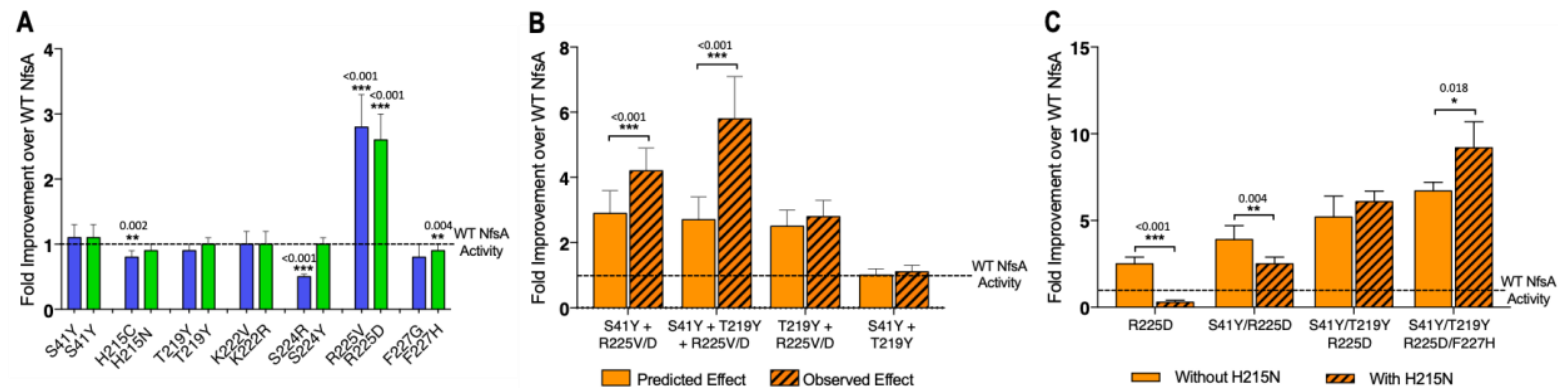

Figure 3: Complex epistatic interactions exist in 36-37 and 20_39. (A) The effect on chloramphenicol detoxification of introducing individual substitutions present in 36_37 (blue) and 20_39 (green) into wild type (WT) NfsA. (B) Observation of epistatic interactions between S41Y, T219Y and R225V/D. The predicted multiplicative effects (solid bars) were calculated by multiplying the fold-increase conferred by individual amino acid substitutions. The error of the predicted effects were derived using an error propagation equation $\left(\delta \mathrm{R}=\mathrm{R} \times \sqrt{\left(\frac{\delta X}{X}\right)^{2}+\left(\frac{\delta Y}{Y}\right)^{2}+\left(\frac{\delta Z}{Z}\right)^{2}}\right.$ where $\delta \mathrm{X}, \delta \mathrm{Y}, \delta \mathrm{Z}$ is the error of $\mathrm{EC}_{50}$ values $\mathrm{X}, \mathrm{Y}$ and $\mathrm{Z}$ and $\delta \mathrm{R}$ is the calculated error of the predicted effect $(\mathrm{R})$ ). Hashed bars reflect the experimentally measured effect of each combination of mutations tested. (C) The effect of recreating the most plausible evolutionary trajectory for $20 \_39$ with (solid bars) or without (hashed bars) the addition of H215N. In all figures an un-paired t-test was used to determine whether there was a significant difference in chloramphenicol detoxification activity between two groups. (***, $p \leq 0.001 ; * *, p \leq 0.01 ; *, p \leq 0.05$ ). Data presented in all figures represent the average of at least four biological repeats \pm 1 S.D. 
We also found evidence of higher-order epistasis beyond the requirement for elimination of R225. For example, both evolved variants contained the substitutions S41Y and T219Y, neither of which conferred a significant improvement in chloramphenicol detoxification when introduced to NfsA individually (Figure 3A) or together (Figure 3B). When each was introduced into an R225V or R225D background, S41Y yielded a significant increase in chloramphenicol detoxification, but T219Y did not (Figure 3B). However, the combination of S41Y and T219Y together with R225V or R225D gave a further significant improvement (Figure 3B). Numerous examples of sign epistasis can also readily be observed in the full network diagram (e.g., the blue circles indicate a negative impact for certain combinations of substitutions; Figure 2D-E, Supplementary Figure S1). For example, H215N (present in variant 20_39) is detrimental to chloramphenicol detoxification activity when substituted into the R225D or R225D/S41Y backgrounds, and somewhat neutral in combination with R225D/S41Y/T291Y, but significantly enhances activity in combination with R225D/S41Y/T291Y/F227H (Figure 3C). Overall, our data suggest that complex epistatic interactions render $>99 \%$ of the possible 5040 evolutionary pathways (that might be traversed from wild type NfsA to either 36_37 or 20_39) broadly inaccessible to iterative mutagenesis strategies.

\section{Improved chloramphenicol detoxification is underpinned by loss of activity with 1,4-} benzoquinone.

The hypothetical evolutionary trajectories depicted in Figure 2F highlight particularly pertinent intermediate combinations of mutations. We considered that interrogating the intermediate variants might shed light on the mechanistic basis of improved chloramphenicol detoxification. In particular, we wanted to determine how activity with a presumed native substrate like 1,4-benzoquinone was affected during the hypothetical evolutionary progression towards improved chloramphenicol detoxification. For this, the enzyme intermediates identified in the most probable stepwise evolutionary trajectory (Figure 2F) were purified as His-tagged proteins and in vitro kinetics assays were conducted with both chloramphenicol and 1,4-benzoquinone (Supplementary Table S1). From this data, it was evident that the first substitution of both hypothetical trajectories (i.e., the elimination of R225; Fig. 3A) was sufficient to abolish nearly all 1,4-benzoquinone activity, which was then unmeasurably low across all subsequent substitutions (Figures 4A and 4E). The sustained loss of 1,4-benzoquinone activity throughout each trajectory strongly suggests that this activity cannot co-exist with chloramphenicol reduction. This is reinforced by examination of 
the chloramphenicol detoxification activities of the complete set of hypothetical evolutionary intermediates (Supplementary Figure S1); the variants that retained R225 were on average no better than wild type NfsA at defending host cells against chloramphenicol (mean foldimprovement of $1.0 \pm 0.5$ ), while cells expressing variants that contained the substitution $\mathrm{R} 225 \mathrm{~V}$ or R225D were on average able to tolerate $4.0 \pm 2.4$ fold higher chloramphenicol concentrations than those expressing wild type $n f s A$ (Table S2).

The substitution S41Y that came next in both trajectories yielded a profound improvement in chloramphenicol $K_{M}$, but also diminished $k_{c a t}$ substantially (Figures $4 \mathrm{~B} \& \mathrm{C}$ and $4 \mathrm{~F} \& \mathrm{G}$ ). We observed the same S41Y NfsA substitution in our previous PR-104A study, and concluded that this most likely enables planar stabilisation and stacking of nitroaromatic substrates between the isoalloxazine rings of flavin mononucleotide (FMN) and the introduced tyrosine (Copp et al., 2017). It is likely that a similar phenomenon explains the improved affinity for chloramphenicol observed here, with the decrease in catalytic turnover also arising as a consequence of enhanced stabilisation of the Michaelis complex. The subsequent substitutions in each trajectory then act to 'tune' the system, exerting only minor effects on $k_{c a t}$, but overall yielding incremental improvements in chloramphenicol $K_{M}$ that largely mirror the improved chloramphenicol detoxification observed in vivo (Figures 4C\&E and 4D\&F). SDS-PAGE analysis confirmed that the expression levels were consistent for each intermediate variant throughout the evolutionary progression, eliminating this as a variable exerting substantial influence on the relative activity levels in vivo (Supplementary Figure S2).

\section{Impact of evolving improved affinity for chloramphenicol on alternate substrates.}

Collectively, the above data suggest that selection of lead variants for enhanced chloramphenicol detoxification within an E. coli cellular context resulted in small gains in catalytic efficiency, driven by substantially improved affinity for chloramphenicol as a substrate, as well as a profound loss of activity for an endogenous competing quinone substrate. We were interested to discover the impact that this may have had on unselected promiscuous activities of NfsA. We therefore used $\mathrm{EC}_{50}$ growth assays to assess the sensitivities of E. coli 7NT strains individually expressing either NfsA, variants 36_37 or 20_39, or the hypothetical evolutionary intermediates thereof, to five structurally diverse nitroaromatic prodrugs (Figure 5). We anticipated that the loss of competitive inhibition by endogenous quinones might have generically enhanced activity with each of these prodrugs, 
bioRxiv preprint doi: https://doi.org/10.1101/2020.05.27.118489; this version posted May 30, 2020. The copyright holder for this preprint (which was not certified by peer review) is the author/funder, who has granted bioRxiv a license to display the preprint in perpetuity. It is made available under aCC-BY 4.0 International license.
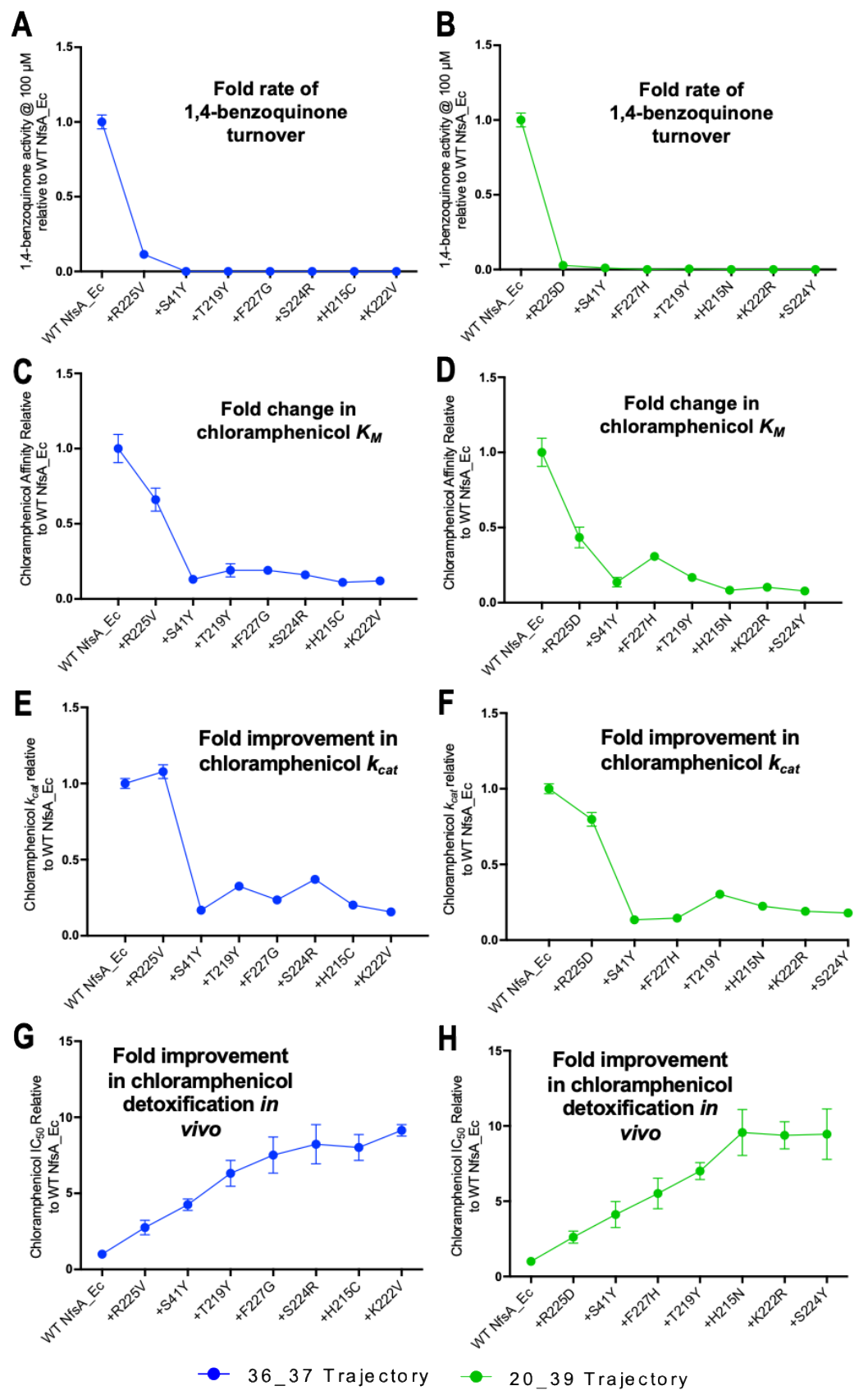

343 Figure 4: Activity analysis with 1,4-benzoquinone (A, B) and chloramphenicol (C-H) during the

344 evolutionary progression of 36_37 (left, blue) and 20_39 (right, green). (A, B) Fold rate of turnover of 1,4345 benzoquinone (starting concentration $100 \mu \mathrm{M}$, with $250 \mu \mathrm{M}$ NADPH co-substrate) relative to wild type NfsA

346 for each intermediate variant in the evolutionary trajectory of 36_37 (A) and 20_39 (B). (C, D) Fold change in 347 chloramphenicol $K_{M}$ relative to wild-type NfsA for each intermediate of 36_37 (C) and 20_39 (D). (E, F) Fold 348 increase in chloramphenicol $k_{\text {cat }}$ relative to wild-type NfsA for each intermediate of 36_37 (E) and 20_39 (F), reproduced for convenience from Figure $2 \mathrm{~F}$. $(\mathbf{G}, \mathbf{H})$ Fold improvement in chloramphenicol detoxification $\left(\mathrm{EC}_{50}\right)$ conferred to $E$. coli 7NT host cells by each variant relative to wild-type NfsA. Full Michaelis-Menten kinetic parameters are shown in Supplementary Table S1. All in vitro data presented is the average of three technical repeats \pm 1 S.D. and all in vivo data presented in the average of at least four biological repeats \pm 1 S.D. 
bioRxiv preprint doi: https://doi.org/10.1101/2020.05.27.118489; this version posted May 30, 2020. The copyright holder for this preprint (which was not certified by peer review) is the author/funder, who has granted bioRxiv a license to display the preprint in perpetuity. It is made available under aCC-BY 4.0 International license.

353

354

355

356

357

358

359

360

361

362

363

364

365

366

367

368

369

370

371

372

373

374

375

376

377

378

379

resulting in heightened host cell toxicity. However, for four of the five prodrugs, host sensitivity was largely unchanged $\left(\mathrm{EC}_{50}\right.$ within a range of 0.8 to 2-fold that of the NfsAexpressing strain) when expressing any of the variants (Figure 5C-F). The exception was metronidazole, for which all variants exhibited similar gains in activity to chloramphenicol, despite the two compounds sharing little structural similarity (Figure 5A-B). Moreover, the introduction of R225V or R225D substitutions into NfsA (which largely eliminate 1,4benzoquinone activity; Figure 4A-B) did not improve reduction of all prodrugs, but only significantly enhanced activity with metronidazole and CB1954 (Student's t-test; Figure 5B,D). We therefore concluded that our selection for enhanced chloramphenicol detoxification was not driven exclusively by loss of the competing quinone activity, as this would have tended to also enhance activity with other alternate substrates.
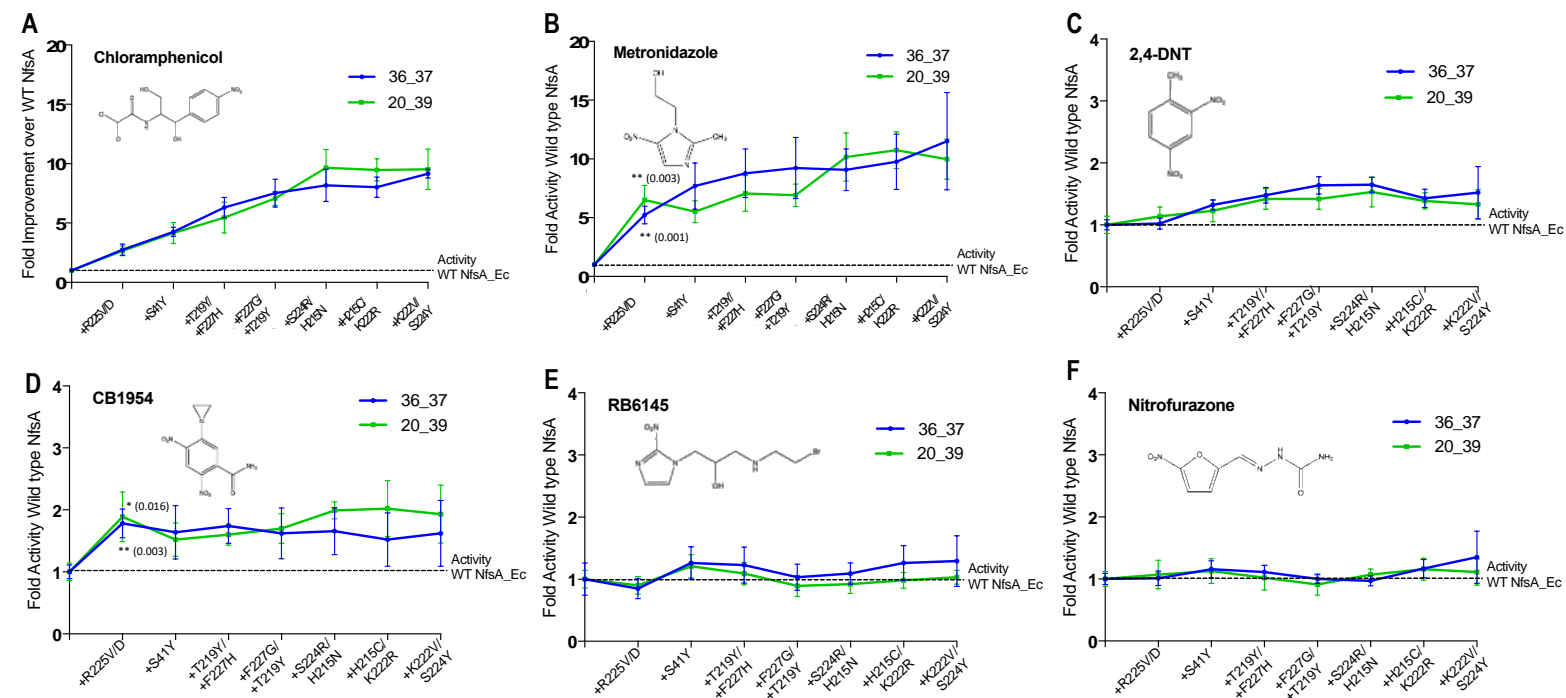

Figure 5: Activity analysis with nitroaromatic prodrugs during the evolutionary progression of 36_37 (blue) and 20_39 (green). E. coli 7NT cells expressing each of the hypothetical intermediate variants of 36_37 and 20_39 were tested in $\mathrm{EC}_{50}$ growth assays for $(\mathbf{A})$ resistance to chloramphenicol; and (B-F) sensitivity to metronidazole, 2,4-DNT, CB1954, RB6145 and nitrofurazone, respectively. Data is presented as the fold improvement relative wild-type NfsA, with the average of four biological repeats \pm 1 S.D. Chloramphenicol (A) and metronidazole $(\mathbf{B})$ data are plotted on a different scale due to the large fold-improvements in activity. Where substitution of R225 caused a significant improvement in prodrug activation (Student's t-test), the $p$ value is noted in the figure panel (above the trendline for variant 20_39, and below for variant 36_37).

\section{Applications of 36_37 and 20_39 as dual selectable / counter-selectable marker genes}

Whereas reduction of chloramphenicol is a detoxifying activity, reduction of metronidazole yields a toxic product. The serendipitous gains in metronidazole sensitivity that paralleled improved chloramphenicol detoxification inspired us to investigate whether these opposing activities might have useful molecular biology applications, by offering dual selectable and 
counter-selectable functionalities in a single gene. Counter-selectable markers, such as the $s a c B$ levansucrase gene from Bacillus subtilis, have multiple applications including the forced elimination of plasmids, and resolution of merodiploid constructs during allele exchange (Stibitz, 1994). However, they must typically be partnered with a selectable marker on the same DNA construct, to enable positive selection for the construct before its subsequent elimination. This occupies additional space, which is undesirable for sizerestricted constructs, and means there is potential for the two genes to become separated by recombination events, leading to false positive or false negative outcomes.

389 Because metronidazole is cheap, widely-available, and has no measurable bystander effect in

390 E. coli (i.e., unlike many other nitroaromatic prodrugs its toxic metabolites are confined solely to the activating cell (Chan-Hyams et al., 2018), we considered it ideally suited for counter-selection applications. We therefore tested the abilities of chloramphenicol to maintain, or metronidazole to force elimination of, plasmids bearing either 36_37 or 20_39 in E. coli 7NT. Cells were cultured for one hour in the absence of any selective compound, then plated on solid media amended with either $5 \mu \mathrm{M}$ chloramphenicol or $10 \mu \mathrm{M}$ metronidazole. The resulting colonies were then tested for retention or loss of the plasmid, respectively, with the expected outcome being realised in $100 \%$ of cases (94/94 colonies tested; Supplementary Figure S3). This suggests that our evolved variants might indeed have useful applications as dual selectable / counter-selectable marker genes.

400

401

\section{Discussion}

By exploiting a powerful selection for antibiotic resistance, we were able to implement simultaneous mass-mutagenesis on an unprecedented scale, to amplify a promiscuous functionality. We acknowledge that this approach of focusing exclusively on eight key active-site residues means the reconstructed NfsA 'engine' is unlikely to be an optimal fit within the pre-existing chassis, and that further gains in activity would undoubtedly result by selecting residue substitutions in the second shell, or beyond. Nevertheless, we reasoned that our approach would allow us to gain comprehensive insight into key catalytic changes driving improved chloramphenicol detoxification, without being subject to the stochastic vagaries of error-prone PCR, or the well-established phenomenon that it can only access a limited and unbalanced repertoire of residues (on average, only 5.7 of the 19 alternative

412 amino acids per codon position, with a bias toward similar residues (Hermes et al., 1990). We

413 also initially considered that this approach might allow us to leap to a fitness peak that 
414

415

416

417

418

419

420

421

422

423

424

425

426

427

428

429

430

431

432

433

434

435

436

437

438

439

440

441

442

443

444

445

446

447

iterative random mutagenesis strategies would be unable to scale. However, when we examined every hypothetical evolutionary intermediate, we discovered this was not the case; although stepwise evolution would have been greatly constrained in the progression from wild type NfsA to either of our top two variants, there were plausible trajectories to achieve these outcomes. Notably, the critical first step in any of these trajectories was the near-total elimination of the native quinone reductase activity, which was never restored and appears incompatible with the evolved activity. This is a very different scenario to the predominantly weak trade-offs observed in previous laboratory evolution studies (e.g., those reviewed by Kaltenbach et al., (2016). Even the more recent work of Ben-David et al., (2020) who encountered an abrupt activity trade-off when they evolved the calcium-dependent lactonase mammalian paraoxonase-1 into an efficient organophosphate hydrolase, found that the native functionality could subsequently be restored and was not incompatible with the evolved one (Ben-David et al., 2013; Ben-David et al., 2020).

By choosing to evolve an enzyme in its native cellular environment, we deliberately set out to explore the additional complexities of metabolic interference, which have potential to play dominant roles in shaping natural evolutionary outcomes. Copley recently described an equation that succinctly summarises how the rate of a promiscuous reaction in the presence of a native substrate might be improved by 1 ) increasing the concentration of the enzyme; 2) increasing the ratio of promiscuous to native substrate; and/or 3) altering the active site to diminish substrate competition, by enhancing binding or turnover of the promiscuous substrate, or decreasing binding of the native substrate (Copley, 2020). In a landmark 2015 study she and co-workers experimentally demonstrated the importance of diminished substrate competition, focusing on a single key Glu to Ala substitution that enabled several orthologs of ProA (L-gamma-glutamyl phosphate reductase, a key enzyme in proline synthesis) to replace E. coli $\mathrm{ArgC}$ (an N-acetyl glutamyl phosphate reductase required for arginine synthesis) (Khanal et al., 2015). Where measurable, all of the substituted variants showed decreased affinity (increased $K_{M}$ ) for the native substrate; and in all but one case there was substantial improvement in $k_{c a} / K_{M}$ for the promiscuous substrate as well (Khanal et al., 2015). These findings are similar to our observation that elimination of quinone reductase activity from NfsA via substitution of R225 provided a platform for successive improvements in chloramphenicol affinity to amplify host cell resistance. Together, these examples support the proposal of Kaltenbach et al., (2016) that during natural evolution of a promiscuous activity there is likely to be active selection against the original function, as well as our own 
supposition that most previous laboratory evolution studies have evaded this phenomenon by focusing on heterologous enzymes and/or exogenously applied substrates. Moreover, our observations that the unselected promiscuous activities of NfsA (reduction of a structurally diverse panel of prodrugs) were mostly unaffected is consistent with their central thesis, that positive selection alone does not lead to specialisation. The emerging picture is that evolution in the natural intracellular milieu involves both selection for the new function, and selection against the old.

An interesting difference between our scenario and that of the Copley team is that NfsA is far less essential to the fitness of its host cell than ProA (e.g., deletion of $n f s A$ does not impair $E$. coli growth even under oxidative stress from heavy metal challenge (Ackerley et al., 2004)). This means that when a new stress is encountered and a promiscuous function becomes essential, as we have modelled here, the enzyme can potentially evolve without necessitating gene duplication to preserve the original function. An apparent "freedom to operate" is manifest in the vast diversity of primary functionalities observed in the superfamily of nitroreductases that NfsA belongs to (which spans activities as divergent as quinone reduction, flavin reduction to power bioluminescence, flavin fragmentation, dehalogenation and dehydrogenation (Akiva et al., 2017)). Although this contrasts with the prevailing Innovation-Amplification-Divergence (IAD) model for natural enzyme evolution (Bergthorsson et al., 2007), it may not be an exceptional scenario - rather, as previously argued by Newton et al., (2015) it is likely that only a minority of enzymes in a cell are under active selection pressure at any time, and redundancy in metabolic networks means that there is latent evolutionary potential that can be immediately tapped to adapt to stress without the requirement of rare and costly gene duplication events. That a single mutation may suffice to rapidly amplify a desirable promiscuous activity simply by eliminating native substrate competition confers substantial 'robustness' at a cellular level, even if it means that individual enzymes may not be as robust as previously considered.

\section{Methods}

\section{Chemicals}

478 Chloramphenicol, metronidazole, 2,4-dinitrotoluene and nitrofurazone were purchased from

479 Sigma-Aldrich. CB1954 was purchased from MedKoo Biosciences. RB6145 was synthesised 480 in-house at the Ferrier Institute, Victoria University of Wellington. 
bioRxiv preprint doi: https://doi.org/10.1101/2020.05.27.118489; this version posted May 30, 2020. The copyright holder for this preprint (which was not certified by peer review) is the author/funder, who has granted bioRxiv a license to display the preprint in perpetuity. It is made available under aCC-BY 4.0 International license.

482

483

484

485

486

487

488

489

490

491

492

493

494

495

496

497

498

499

500

501

502

503

504

505

506

507

508

509

510

511

512

513

514

515

\section{Simultaneous Site-Directed Mutagenesis Library Construction and Selection}

To randomise the eight targeted residues of NfsA_Ec (S41, L43, H215, T219, K222, S224, R225 and F227) we designed a degenerate gene construct with NDT codons (specifying Arg, Asn, Asp, Cys, Gly, His, Ile, Leu, Phe, Ser, Tyr and Val) at all positions other than 219 (NHT codon, encoding Ala, Asn, Asp, His, Ile, Leu, Phe, Pro, Ser, Thr, Tyr and Val) and 222 (VNG codon, encoding Ala, Gln, Glu, Gly, Leu, Lys, Met, Pro, Thr, Val and two Arg codons). Initially a synthetic gene library was ordered from Lab Genius pre-cloned into plasmid pUCX (Prosser et al., 2013), however this only yielded 15\% of the 252 million unique variants in our final collection. The remaining $85 \%$ were generated ourselves by ordering the same sequence as a gene fragment library from GenScript and ligating it into pUCX at the NdeI and SalI restriction sites. The combined libraries were used to transform $E$. coli $7 \mathrm{NT}$, a derivative of strain W3110 bearing gene deletions of seven endogenous nitroreductases $(n f s A$, $n f s B, a z o R$, nemA, yieF, ycaK and $m d a B$ ) and the tolC efflux pump (Copp et al., 2014).

Electrocompetent $E$. coli 7NT cells were generated as per Sambrook and Russell (2001), and the transformation efficiency was enhanced using a yeast tRNA protocol modified from Zhu and Dean, (1999). Library selection was conducted on selective solid media containing LB agar supplemented with $100 \mu \mathrm{g} . \mathrm{mL}^{-1}$ ampicillin and either 45 or $47.5 \mu \mathrm{M}$ chloramphenicol. Appropriate dilutions of the pooled library stock were spread over plates and incubated at 37 ${ }^{\circ} \mathrm{C}$ for 40 hours. Dilutions of the library were also spread over non-selective solid media (LB agar supplemented with $100 \mu \mathrm{g} . \mathrm{mL}^{-1}$ ampicillin) to estimate the number of transformants included in each selection. Enzyme intermediates of NfsA_Ec 36_37 and 20_39 were ordered as synthetic gene fragments from Twist Biosciences and subsequently ligated into the NdeI and SalI restriction sites of the vectors pUCX (for $\mathrm{EC}_{50}$ analysis) or $\mathrm{pET} 28(\mathrm{a})^{+}$(for purification of His $_{6}$-tagged proteins).

\section{Growth Assays}

For growth inhibition assays, a 96-well microtitre plate with wells containing $200 \mu \mathrm{L} \mathrm{LB}$ medium supplemented with $0.2 \%$ glucose (w/v) and $100 \mu \mathrm{g} \cdot \mathrm{mL}^{-1}$ ampicillin was inoculated with $E$. coli 7 NT nitroreductase strains and incubated at $30{ }^{\circ} \mathrm{C}$ with shaking at $200 \mathrm{rpm}$ for 16 hours. A $15 \mu \mathrm{L}$ sample of overnight culture was used to inoculate $200 \mu \mathrm{L}$ of induction media (LB supplemented with $100 \mu \mathrm{g} \cdot \mathrm{mL}^{-1}$ ampicillin, $0.2 \%$ (w/v) glucose and $50 \mu \mathrm{M}$ IPTG) in each well of a fresh microtitre plate, which was then incubated at $30{ }^{\circ} \mathrm{C}, 200 \mathrm{rpm}$ for 2.5 hours. Aliquots of $30 \mu \mathrm{L}$ apiece from these cultures were used to inoculate four wells of a 384-well plate (two wells containing $30 \mu \mathrm{L}$ induction media and two wells containing $30 \mu \mathrm{L}$ 
induction media supplemented with $2 \times$ the desired chloramphenicol concentration). The cultures were incubated at $30^{\circ} \mathrm{C}, 200 \mathrm{rpm}$ for 4 hours. Cell turbidity was monitored by

518 optical density at $600 \mathrm{~nm}$ prior to drug challenge and 4 hours post challenge. The percentage growth inhibition was determined by calculating the relative increase in $\mathrm{OD}_{600}$ for challenged versus control wells.

522 For $\mathrm{EC}_{50}$ growth assays, $100 \mu \mathrm{L}$ of overnight cultures as above were used to inoculate $2 \mathrm{~mL}$ 523 of induction media and incubated at $30{ }^{\circ} \mathrm{C}, 200 \mathrm{rpm}$ for 2.5 hours. A $30 \mu \mathrm{L}$ sample of each culture was added to wells of a 384-well plate containing $30 \mu \mathrm{L}$ of induction media supplemented with $2 \times$ the final prodrug concentration. Each culture was exposed to 7-15 drug concentrations representing a 1.5-fold dilution series of drug and one unchallenged (induction media only) control. The cultures were incubated at $30{ }^{\circ} \mathrm{C}, 200 \mathrm{rpm}$ for 4 hours.

528 Cell turbidity was monitored by optical density at $600 \mathrm{~nm}$ prior to drug challenge and 4 hours post challenge. The $\mathrm{EC}_{50}$ value of technical replicates was calculated using a dose-response inhibition four-parameter variable slope equation in GraphPad Prism 8.0. The $\mathrm{EC}_{50}$ values of biological replicates were averaged to provide a final $\mathrm{EC}_{50}$ value.

\section{Evolutionary Trajectory Analysis}

534 Full details of how the evolutionary trajectory analysis was conducted are available at

535 https://github.com/MarkCalcott/Analyse_epistatic_interactions/tree/master/Create_mutation network.

\section{Protein Purification and Steady-State Kinetics}

539 Recombinant nitroreductases were cloned into the His ${ }_{6}$-tagged expression vector pET28(a) ${ }^{+}$,

540 expressed in BL21 and purified as His $_{6}$-tagged proteins. Enzyme reactions were carried out in $54160 \mu \mathrm{L}$ reactions in $96-w e l l$ plates with a $4.5 \mathrm{~mm}$ pathlength. All reactions were performed in $54210 \mathrm{mM}$ Tris $\mathrm{HCl}$ buffer $\mathrm{pH}$ 7.0, $250 \mu \mathrm{M}$ NADPH, an appropriate dilution of chloramphenicol 543 or 1,4-benzoquinone substrate dissolved in DMSO $(0-4000 \mu \mathrm{M}$ chloramphenicol and $100 \mu \mathrm{M}$ 544 1,4-benzoquinone), made up to volume with $\mathrm{ddH}_{2} \mathrm{O}$. Reactions were initiated with the added of $6 \mu \mathrm{L}$ of enzyme ( $8 \mu \mathrm{M}$ or an appropriate concentration) and the linear decrease in

546 absorbance was monitored at $340 \mathrm{~nm}$ measuring the rate of NADPH depletion as an indirect

547 measured of substrate reduction. As neither chloramphenicol nor 1,4-benzoquinone interfere

548 with the absorbance at $340 \mathrm{~nm}$, the extinction coefficient of NADPH at $340 \mathrm{~nm}$ was used (chloramphenicol = 12,400 $\mathrm{M}^{-1} \mathrm{~cm}^{-1}$ and $p$-benzoquinone $=6,220 \mathrm{M}^{-1} \mathrm{~cm}^{-1}$, as two molecules 
of NADPH are required to reduce chloramphenicol to the hydroxylamine form, while only one is required for the reduction of $p$-benzoquinone to the quinol). Technical replicates were plotted using Graphpad Prism 8.0 software and non-linear regression analysis and MichaelisMenten curve fitting was performed.

\section{SDS-PAGE analysis for key intermediate NfsA variants}

E. coli 7 NT pUCX::nfs $A$ variant strains were used to inoculate $200 \mu \mathrm{L}$ LB media supplemented with $0.2 \%(\mathrm{w} / \mathrm{v})$ glucose and Amp. Cultures were incubated overnight at 30 ${ }^{\circ} \mathrm{C}, 200 \mathrm{rpm}$. The next day, $100 \mu \mathrm{L}$ of the overnight culture was used to inoculate $2 \mathrm{~mL}$ of LB induction medium (LB supplemented with $0.2 \%$ (w/v) glucose, Amp and $50 \mu \mathrm{M}$ IPTG). Day cultures were grown at $30{ }^{\circ} \mathrm{C}, 200 \mathrm{rpm}$ for 6.5 hours, after which the cultures were pelleted by centrifugation at $2500 \times g$ for $5 \mathrm{~min}$. The supernatant was decanted and the cell pellets resuspended in $\sim 100 \mu \mathrm{L}$ of $\mathrm{LB}$ medium, after which the $\mathrm{OD}_{600}$ of a 1:100 dilution was measured. Cell cultures were normalised by dilution with additional LB medium so that a 1 in 100 dilution would give an $\mathrm{OD}_{600}$ reading of 0.1 . A $12 \mu \mathrm{L}$ sample of each culture was mixed with $5 \times$ SDS loading buffer, heated at $95^{\circ} \mathrm{C}$ for $5 \mathrm{~min}$ and subjected to SDS-PAGE analysis on a $15 \%$ acrylamide gel.

\section{Evaluating the selection / counter-selection potential of evolved $\boldsymbol{n f s} \boldsymbol{A}$ variants}

A single colony of an E. coli 7NT cells expressing $n f s A \_E c$ 36_37 or 20_39 was used to inoculate a $3 \mathrm{~mL}$ overnight culture of LB supplemented with $100 \mu \mathrm{g} \cdot \mathrm{mL}^{-1}$ ampicillin. The next day, $100 \mu \mathrm{L}$ of each overnight culture was used to inoculate $10 \mathrm{~mL}$ fresh $\mathrm{LB}$ medium in a $125 \mathrm{~mL}$ baffled conical flask. The culture was grown at $37^{\circ} \mathrm{C}, 200 \mathrm{rpm}$ for 1 hour then the $\mathrm{OD}_{600}$ of the flask was determined. An appropriate dilution of each culture was plated on agar plates containing either LB-only, or LB amended with $10 \mu \mathrm{M}$ metronidazole or $5 \mu \mathrm{M}$ chloramphenicol. At $10 \mu \mathrm{M}$ metronidazole, cells expressing NfsA_Ec 36_37 or 20_39 could not grow but cells bearing no plasmid could, while the reverse scenario applied with $5 \mu \mathrm{M}$ chloramphenicol. Plates were incubated at $37{ }^{\circ} \mathrm{C}$ for 16 hours (LB-only or LB + metronidazole) or 40 hours (LB + chloramphenicol). To confirm the presence/absence of the plasmid bearing 36_37 or 20_39, 47 colonies from each condition were streaked on LB agar plates supplemented with $100 \mu \mathrm{g} . \mathrm{mL}^{-1}$ ampicillin and incubated at $37^{\circ} \mathrm{C}$ for 16 hours, with growth indicating presence of the plasmid and no growth indicating absence of the plasmid. 
bioRxiv preprint doi: https://doi.org/10.1101/2020.05.27.118489; this version posted May 30,2020 . The copyright holder for this preprint (which was not certified by peer review) is the author/funder, who has granted bioRxiv a license to display the preprint in perpetuity. It is made available under aCC-BY 4.0 International license.

583

584

585

586

587

588

589

590

591

592

593

594

595

596

597

598

599

600

601

602

603

604

605

606

607

608

609

610

611

612

613

614

615

616

617

618

619

620

621

622

$n f s A \_$Ec forward and reverse specific primers (Prosser et al., 2013). A band approximately $720 \mathrm{bp}$ indicated presence of the plasmid, while no band indicated absence of the plasmid.

\section{Statistical Analysis}

Unless otherwise stated, data are given as the mean \pm standard deviation. The software programme GraphPad Prism 8.0 was used for all statistical analyses. Differences between measured $\mathrm{EC}_{50}$ values of enzyme variants were determined by an unpaired Student's t-test. A p-value of $\leq 0.05$ was considered statistically significant with $* * *=$ p-value $\leq 0.001, * *=$ p-value $\leq 0.01$ and $*=$-value $\leq 0.05$.

\section{Acknowledgements}

We thank Professor Dan Tawfik for insightful suggestions on shaping the research and Associate Professor Nobu Tokuriki for his comments on an early draft of the manuscript.

This research was funded by The Royal Society of New Zealand Marsden Fund (contract 15VUW-037 to DFA and WMP, including a PhD scholarship for KRH). MHR received additional support from a Victoria University of Wellington (VUW) Doctoral Scholarship, RFL a VUW Masters Scholarship, and MJC from a research grant awarded by the Cancer Society of New Zealand (grant 18.05 to MJC and DFA).

\section{References}

Ackerley DF, Gonzalez CF, Keyhan M, Blake R $2^{\text {nd }}$, Matin A. 2004. Mechanism of chromate reduction by the Escherichia coli protein, $\mathrm{Nfs} A$, and the role of different chromate reductases in minimizing oxidative stress during chromate reduction. Environmental Microbiology 6:851-860. DOI: https://doi.org/10.1111/j.1462-2920.2004.00639.x

Aharoni A, Gaidukov L, Khersonsky O, Mc Gould S, Roodveldt C, Tawfik DS. 2005. The 'evolvability' of promiscuous protein functions. Nature Genetics 37:73-76. DOI: https://doi.org/10.1038/ng1482

Akiva E, Copp JN, Tokuriki N, Babbitt PC. 2017. Evolutionary and molecular foundations of multiple contemporary functions of the nitroreductase superfamily. Proceedings of the National Academy of Sciences USA 114:e9549-9558. DOI: https://doi.org/10.1073/pnas.1706849114

Ben-David M, Soskine M, Dubovetskyi A, Cherukuri KP, Dym O, Sussman JL, Liao Q, Szeler K, Kamerlin SCL, Tawfik DS. 2020. Enzyme Evolution: An Epistatic Ratchet versus a Smooth Reversible Transition. Molecular Biology Evolution 37:1133-1147. DOI: https://doi.org/10.1093/molbev/msz298

Ben-David M, Wieczorek G, Elias M, Silman I, Sussman JL, Tawfik DS. 2013. Catalytic metal ion rearrangements underline promiscuity and evolvability of a metalloenzyme. Journal of Moleulcar Biology 425:1028-1038. DOI: https://doi.org/10.1016/j.jmb.2013.01.009 
bioRxiv preprint doi: https://doi.org/10.1101/2020.05.27.118489; this version posted May 30, 2020. The copyright holder for this preprint (which was not certified by peer review) is the author/funder, who has granted bioRxiv a license to display the preprint in perpetuity. It is made available under aCC-BY 4.0 International license.

623 Bergthorsson U, Andersson DI, Roth JR. 2007. Ohno's dilemma: evolution of new genes under continuous selection. Proceedings of the National Academy of Sciences USA 104:17004-17009. DOI: https://doi.org/10.1073/pnas.0707158104

Chan-Hyams JVE, Copp JN, Smaill JB, Patterson AV, Ackerley DF. 2018. Evaluating the abilities of diverse nitroaromatic prodrug metabolites to exit a model Gram negative vector for bacterialdirected enzyme-prodrug therapy. Biochemical Pharmacology 158:192-200. DOI:

630

631

632

633

634

635

636

637

638

639

640

641

642

643 https://doi.org/10.1016/j.bcp.2018.10.020

Copley SD. 2009. Evolution of efficient pathways for degradation of anthropogenic chemicals. Nature Chemical Biology 5:559-566. DOI: https://doi.org/10.1038/nchembio.197

Copley SD. 2015. An evolutionary biochemist's perspective on promiscuity. Trends in Biochemical Sciences 40:72-78. DOI: https://doi.org/10.1016/j.tibs.2014.12.004

Copley SD. 2020. Evolution of new enzymes by gene duplication and divergence. The FEBS Journal 287:1262-1283. DOI: https://doi.org/10.1111/febs.15299

Copp JN, Mowday AM, Williams EM, Guise CP, Ashoorzadeh A, Sharrock AV, Flanagan JU, Smaill JB, Patterson AV, Ackerley DF. 2017. Engineering a multifunctional nitroreductase for improved activation of prodrugs and PET probes for cancer gene therapy. Cell Chemical Biology 24:391-403. DOI: https://doi.org/10.1016/j.chembiol.2017.02.005

Copp JN, Pletzer D, Brown AS, Van der Heijden J, Miton CM, Edgar RJ, Rich MH, Little RF, Williams EM, Hancock REW, Tokuriki N, Ackerley DF. 2020. Mechanistic understanding enables the rational design of salicylanilide combination therapies for Gram-negative infections. bioRxiv DOI:

649 https://doi.org/10.1101/2020.04.23.058875

650

651

652

653

654

655

656

657

658

659

660

661

662

663

664

665

Copp JN, Williams EM, Rich MH, Patterson AV, Smaill JB, Ackerley DF. 2014. Toward a highthroughput screening platform for directed evolution of enzymes that activate genotoxic prodrugs. Protein Engineering, Design and Selection 27:399-403. DOI: https://doi.org/10.1093/protein/gzu025

Crofts TS, Sontha P, King AO, Wang B, Biddy BA, Zanolli N, Gaumnitz J, Dantas G. 2019. Discovery and characterization of a nitroreductase capable of conferring bacterial resistance to chloramphenicol. Cell Chemical Biology 26:559-570. DOI: https://doi.org/10.1016/j.chembiol.2019.01.007

Hall BG. 2004. Predicting the evolution of antibiotic resistance genes. Nature Reviews Microbiology 2:430-435. DOI: https://doi.org/10.1038/nrmicro888

Hermes JD, Blacklow SC, Knowles JR. 1990. Searching sequence space by definably random mutagenesis: improving the catalytic potency of an enzyme. Proceedings of the National Academy of Sciences USA 87:696-700. DOI: https://doi.org/10.1073/pnas.87.2.696

Kaltenbach M, Emond S, Hollfelder F, Tokuriki N. 2016. Functional Trade-Offs in Promiscuous Enzymes Cannot Be Explained by Intrinsic Mutational Robustness of the Native Activity. PLOS Genetics 12:e1006305. DOI: https://doi.org/10.1371/journal.pgen.1006305

670 Kaltenbach M, Jackson CJ, Campbell EC, Hollfelder F, Tokuriki N. 2015. Reverse evolution leads to 671 genotypic incompatibility despite functional and active site convergence. Elife 4:e06492.

672 https://doi.org/10.7554/eLife.06492.001 
bioRxiv preprint doi: https://doi.org/10.1101/2020.05.27.118489; this version posted May 30, 2020. The copyright holder for this preprint (which was not certified by peer review) is the author/funder, who has granted bioRxiv a license to display the preprint in perpetuity. It is made available under aCC-BY 4.0 International license.

674 Kaltenbach M, Tokuriki N. 2014. Dynamics and Constraints of Enzyme Evolution. Journal of

675 Experimental Zoology Part B-Molecular and Developmental Evolution 322:468-487. DOI:

676 https://doi.org/10.1002/jez.b.22562

677

678

679

680

681

682

683

684

685

686

687

688

689

690

691

692

693

694

695

696

697

698

699

700

701

702

703

704

705

706

707

708

709

710

711

712

713

714

715

716

717

718

719

720

721

722

723

724
Khanal A, McLoughlin SY, Kershner JP, Copley SD. 2015. Differential Effects of a Mutation on the Normal and Promiscuous Activities of Orthologs: Implications for Natural and Directed Evolution. Molecular Biology and Evolution 32:100-108. DOI: https://doi.org/10.1093/molbev/msu271

Khersonsky O, Tawfik DS. 2010. Enzyme Promiscuity: A Mechanistic and Evolutionary Perspective. Annual Review of Biochemistry 79:471-505. DOI: https://doi.org/10.1146/annurev-biochem-030409$\underline{143718}$

Kobori T, Sasaki H, Lee WC, Zenno S, Saigo K, Murphy MEP, Tanokura M. 2001. Structure and sitedirected mutagenesis of a flavoprotein from Escherichia coli that reduces nitrocompounds Alteration of pyridine nucleotide binding by a single amino acid substitution. Journal of Biological Chemistry 276:2816-2823. DOI: https://doi.org/10.1074/jbc.M002617200

Liochev SI, Hausladen A, Fridovich I. 1999. Nitroreductase A is regulated as a member of the soxRS regulon of Escherichia coli. Proc Natl Acad Sci USA 96:3537-3539. DOI:

http://doi.org/10.1073/pnas.96.7.3537

Newton MS, Arcus VL, Patrick WM. 2015. Rapid bursts and slow declines: on the possible evolutionary trajectories of enzymes. Journal of the Royal Society Interface 12:20150036. DOI: https://doi.org/10.1098/rsif.2015.0036

O'Brien PJ, Herschlag D. 1999. Catalytic promiscuity and the evolution of new enzymatic activities. Chemical Biology 6:R91-R105. DOI: https://doi.org/10.1016/S1074-5521(99)80033-7

Parry R, Nishino S, Spain J. 2011. Naturally-occurring nitro compounds. Natural Product Reports 28:152-167. DOI: https://doi.org/10.1039/c0np00024h

Paterson ES, Boucher SE, Lambert IB. 2002. Regulation of the $n f s A$ Gene in Escherichia coli by SoxS. Journal of Bacteriology 184:51-58. DOI: https://doi.org/10.1128/jb.184.1.51-58.2002

Patrick WM, Firth AE, Blackburn JM. 2003. User-friendly algorithms for estimating completeness and diversity in randomized protein-encoding libraries. Protein Engineering 16:451-457. DOI:

https://doi.org/10.1093/protein/gzg057

Poelwijk FJ, Tanase-Nicola S, Kiviet DJ, Tans SJ. 2011. Reciprocal sign epistasis is a necessary condition for multi-peaked fitness landscapes. Journal of Theoretical Biology 272:141-144. DOI: https://doi.org/10.1016/i.jtbi.2010.12.015

Prosser GA, Copp JN, Mowday AM, Guise CP, Syddall SP, Williams EM, Horvat CN, Swe PM, Ashoorzadeh A, Denny WA, Smaill JB, Patterson AV, Ackerley DF. 2013. Creation and screening of a multi-family bacterial oxidoreductase library to discover novel nitroreductases that efficiently activate the bioreductive prodrugs CB1954 and PR-104A. Biochemical Pharmacology 85:1091-1103. DOI: https://doi.org/10.1016/j.bcp.2013.01.029

Ramos JL, Gonzalez-Perez MM, Caballero A, van Dillewijn P. 2005. Bioremediation of polynitrated aromatic compounds: plants and microbes put up a fight. Current Opinion in Biotechnology 16:275281. DOI: https://doi.org/10.1016/j.copbio.2005.03.010 
bioRxiv preprint doi: https://doi.org/10.1101/2020.05 27.118489; this version posted May 30, 2020. The copyright holder for this preprint (which was not certified by peer review) is the author/funder, who has granted bioRxiv a license to display the preprint in perpetuity. It is made available under aCC-BY 4.0 International license.

Reetz MT, Kahakeaw D, Lohmer R. 2008. Addressing the numbers problem in directed evolution. ChemBioChem 9:1797-1804. DOI: https://doi.org/10.1002/cbic.200800298

Rich MH. 2017. Discovery and directed evolution of nitroreductase enzymes for activation of prodrufs and PET imaging compounds (PhD thesis). Victoria University of Wellington, Wellington, New Zealand.

Sambrook JF, Russell DW. 2001. Molecular cloning: a laboratory manual. Cold Spring Harbor Laboratory Press (eds). 3rd Edition. ISBN-10 0-87969-577-3

Smith AL, Erwin AL, Kline T, Unrath WCT, Nelson K, Weber A, Howald WN. 2007. Chloramphenicol is a substrate for a novel nitroreductase pathway in Haemophilus influenzae. Antimicrobial Agents and Chemotherapy 51:2820-2829. DOI: https://doi.org/10.1128/Aac.00087-07

Stibitz S. 1994. Use of Conditionally Counterselectable Suicide Vectors for Allelic Exchange. Methods in Enzymology 235:458-465. DOI: https://doi.org/10.1016/0076-6879(94)35161-9

Valiauga B, Williams EM, Ackerley DF, Cenas N. 2017. Reduction of quinones and nitroaromatic compounds by Escherichia coli nitroreductase $\mathrm{A}(\mathrm{Nfs} A)$ : characterization of kinetics and substrate specificity. Archives of Biochemistry and Biophysics 614:14-22. DOI:

https://doi.org/10.1016/j.abb.2016.12.005

Weinreich DM, Watson RA, Chao L. 2005. Perspective: sign epistasis and genetic constraint on evolutionary trajectories. Evolution 59:1165-1174. DOI: https://doi.org/10.1111/j.0014$\underline{3820.2005 . t b 01768 . x}$

Williams EM. 2013. Development of bacterial nitroreductase enzymes for noninvasive imaging in cancer gene therapy (PhD thesis). Victoria University of Wellington, Wellington, New Zealand. DOI: http://hdl.handle.net/10063/4994

Williams EM, Little RF, Mowday AM, Rich MH, Chan-Hyams JV, Copp JN, Smaill JB, Patterson AV, Ackerley DF. 2015. Nitroreductase gene-directed enzyme prodrug therapy: insights and advances toward clinical utility. Biochemical Journal 471:131-153. DOI: https://doi.org/10.1042/BJ20150650

Winkler R, Hertweck C. 2007. Biosynthesis of nitro compounds. ChemBioChem 8:973-977. DOI: https://doi.org/10.1002/cbic.200700042

Yang G, Anderson DW, Baier F, Dohmen E, Hong N, Carr PD, Kamerlin SCL, Jackson CJ, BornbergBauer E, Tokuriki N. 2019. Higher-order epistasis shapes the fitness landscape of a xenobioticdegrading enzyme. Nature Chemical Biology 15:1120-1128. DOI: https://doi.org/10.1038/s41589$\underline{019-0386-3}$

Yunis AA. 1988. Chloramphenicol: relation of structure to activity and toxicity. Annual Review of Pharmacology and Toxicology 28:83-100. DOI:

https://doi.org/10.1146/annurev.pa.28.040188.000503

Zhu H, Dean RA. 1999. A novel method for increasing the transformation efficiency of Escherichia coli application forbacterial artificial chromosome library construction. Nucleic Acids Research 27:910-911. DOI: https://doi.org/10.1093/nar/27.3.910 
bioRxiv preprint doi: https://doi.org/10.1101/2020.05.27.118489; this version posted May 30, 2020. The copyright holder for this preprint (which was not certified by peer review) is the author/funder, who has granted bioRxiv a license to display the preprint in perpetuity. It is made available under aCC-BY 4.0 International license.

\section{Supplementary Figures}

\section{A 36_37 Evolutionary Network}

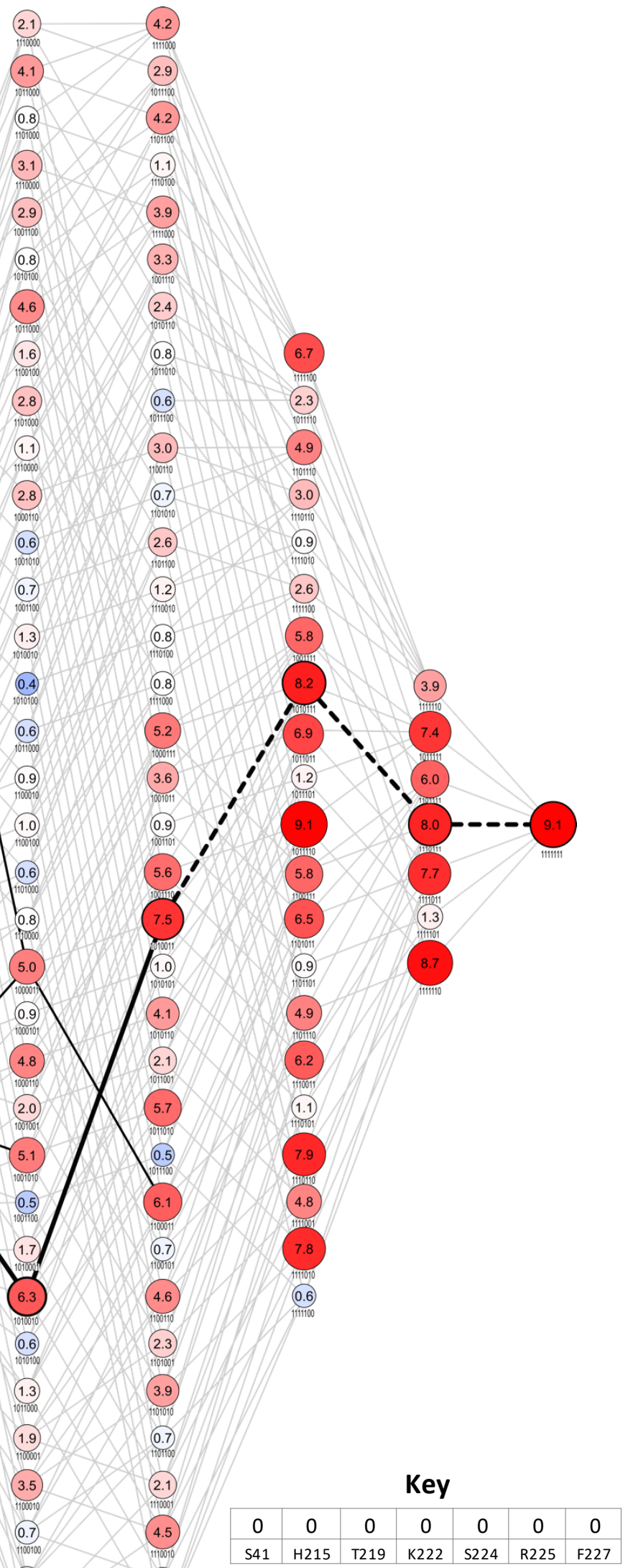

\begin{tabular}{|c|c|c|c|c|c|c|}
\hline 1 & 1 & 1 & 1 & 1 & 1 & 1 \\
\hline S41Y & H215C & T219Y & K222V & S224R & R225V & F227G \\
\hline
\end{tabular}


bioRxiv preprint doi: https://doi org/10.1101/2020 05.27 118489. this version posted May 30,2020. The copyright holder for this preprint (which was not certified by peer review) is the author/funder, who has granted bioRxiv a license to display the preprint in perpetuity. It is made available under aCC-BY 4.0 International license.

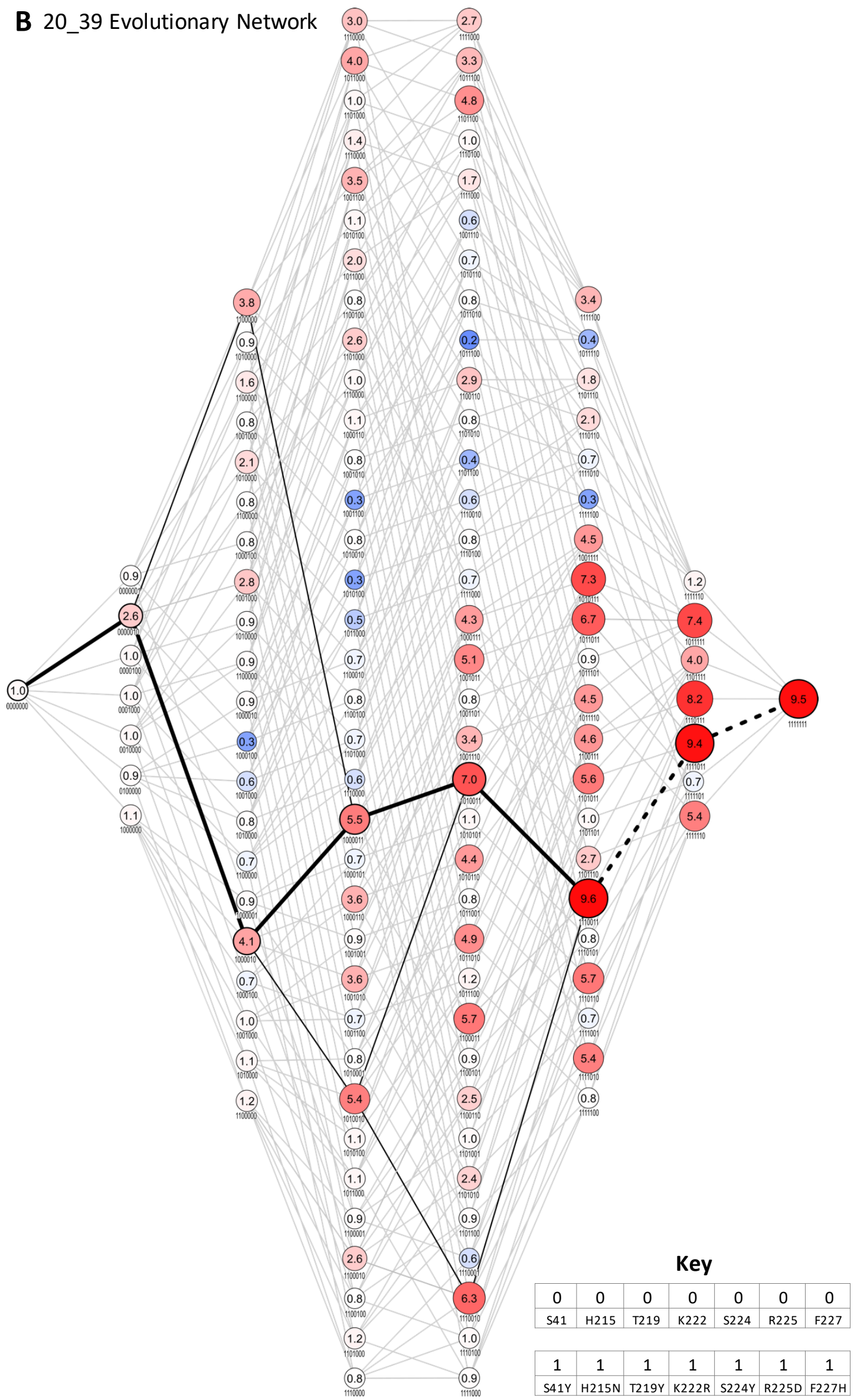


bioRxiv preprint doi: https://doi.org/10.1101/2020 05.27.118489; this version posted May 30, 2020. The copyright holder for this preprint (which was not certified by peer review) is the author/funder, who has granted bioRxiv a license to display the preprint in perpetuity. It is made available under aCC-BY 4.0 International license.

Supplementary Figure S1: Evolutionary network of 36_37 and 20_39. Summary of all possible evolutionary trajectories for both (A) 36_37 and (B) 20_39. Each node represents an enzyme intermediate, with the substitutions present in the intermediate indicated by the presence (1) or absence (0) of the substitutions S41Y, H115C/N, T219Y, K222V/R, S224R/Y, R225V/D, F227G/H. respectively. The numbers within each node represent the fold activity relative to wild-type NfsA measured in E. coli $\mathrm{EC}_{50}$ assays; to facilitate rapid evaluation, the fold-activity for each node is also represented by the area of the circle, and by a colour-code (progressively less activity than wild-type NfsA in brighter shades of blue, and progressively more activity than wild-type NfsA in brighter shades of red). All 5040 possible evolutionary trajectories are marked by grey connecting lines. If a substitution resulted in a $\geq 16 \%$ increase in activity, the edge connecting the two nodes is shown in black ( $16 \%$ being greater than the average error for each set of 128 intermediates). The most probable stepwise mutagenesis pathway (shown in Figure 2D) is shown as thick black lines. A dotted line indicates that a substitution did not result in a $\geq 16 \%$ increase in activity, but formed part of the most probable stepwise mutagenesis evolutionary trajectory. 
bioRxiv preprint doi: https://doi.org/10.1101/2020 05.27.118489; this version posted May 30, 2020. The copyright holder for this preprint (which was not certified by peer review) is the author/funder, who has granted bioRxiv a license to display the preprint in perpetuity. It is made available under aCC-BY 4.0 International license.
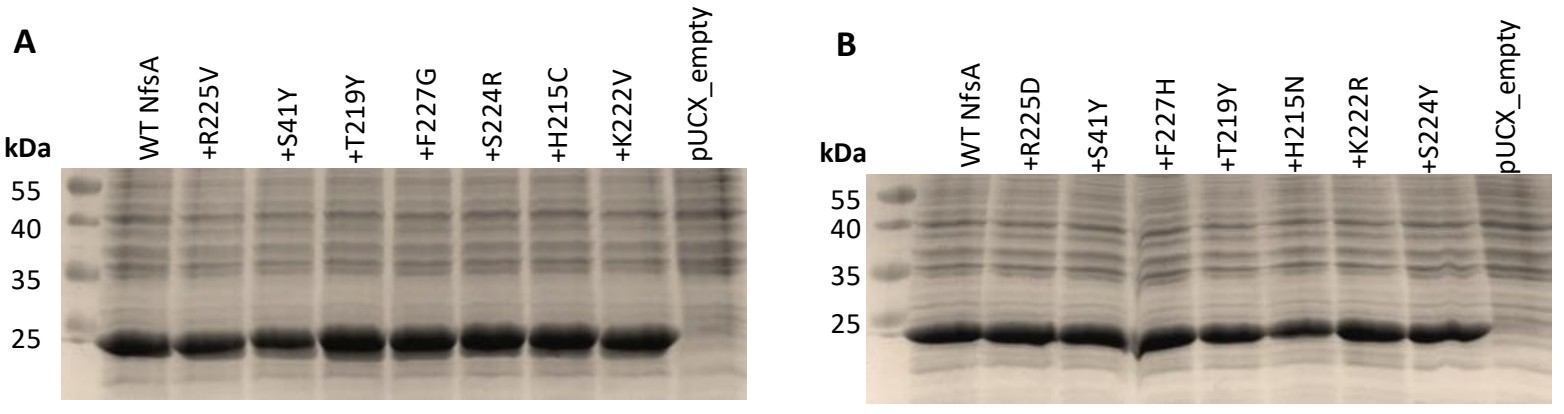

Supplementary Figure S2: Relative enzyme expression levels for key intermediates from the most plausible trajectories for (A) 36_37 and (B) 20_39. Overnight $E$. coli 7NT cultures expressing pUCX::nfsA constructs were used to inoculate LB medium amended with $50 \mu \mathrm{M}$ IPTG and incubated for 6.5 hours at $30^{\circ} \mathrm{C}$. Samples were normalised based on cell density $\left(\mathrm{OD}_{600}\right)$. On each gel, lysate from the cells expressing wild-type $n f s A$ was loaded in the left-most lane relative to the markers, then the strain expressing the R225V/D mutant, then the S41Y R225V/D double mutant, and so on, as indicated by the labels denoting each successive substitution. An E. coli strain bearing empty pUCX was included in the right-most lane as a negative control. The predicted molecular mass of $\mathrm{NfsA}$ is $26.8 \mathrm{kDa}$. 
bioRxiv preprint doi: https://doi org/10.1101/2020.05.27 118489; this version posted May 30, 2020. The copyright holder for this preprint (which was not certified by peer review) is the author/funder, who has granted bioRxiv a license to display the preprint in perpetuity. It is made available under aCC-BY 4.0 International license.

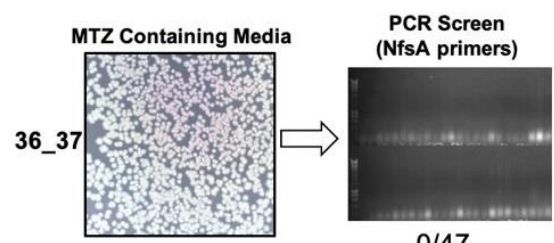

$0 / 47$

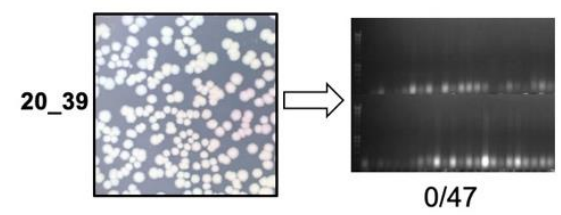

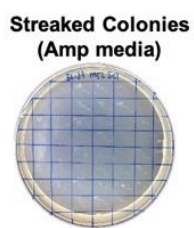

$0 / 47$

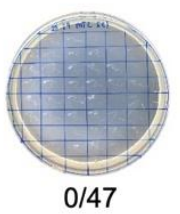

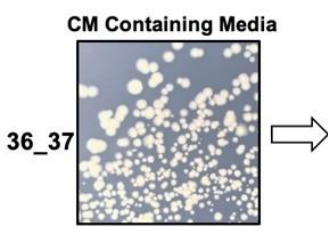

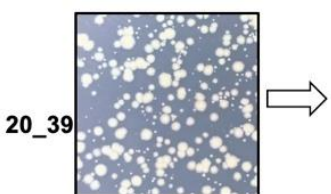

PCR Screen
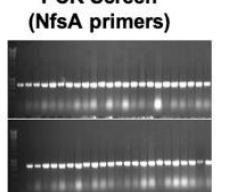

$47 / 47$

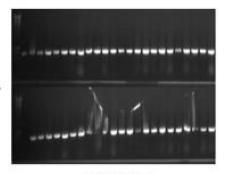

$47 / 47$

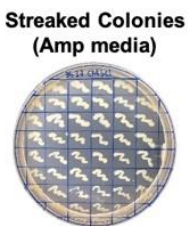

47/47

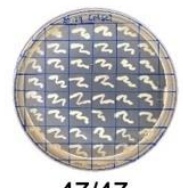

$47 / 47$

Supplementary Figure S3: Growth of 36_37 and 20_39 on selective or counter-selective media. An overnight culture of $36 \_37$ or 20_39 was added to a 1 in 100 dilution to a flask containing LB with no antibiotic or other selective compound. The culture was grown at $37^{\circ} \mathrm{C} 200 \mathrm{rpm}$ for 1 hour and then an appropriate dilution was plated over agar plates containing LB-only, $10 \mu \mathrm{M}$ metronidazole (MTZ) or $5 \mu \mathrm{M}$ chloramphenicol (CM). LB-only and MTZ plates were incubated at $37^{\circ} \mathrm{C}$ for 16 hours, while CM plates were incubated for 40 hours. Forty-seven colonies from the MTZ and CM-containing plates, alongside a negative control were PCR screened with NfsA_Ec specific primers and streaked on media containing ampicillin (Amp) to provide a secondary indication of whether the plasmid bearing the nitroreductase gene was present. 
bioRxiv preprint doi: https://doi.org/10.1101/2020.05.27.118489; this version posted May 30, 2020. The copyright holder for this preprint (which was not certified by peer review) is the author/funder, who has granted bioRxiv a license to display the preprint in perpetuity. It is made available under aCC-BY 4.0 International license.

\begin{tabular}{rcccc}
\hline A 36_37 & $\boldsymbol{k}_{\text {cat }}\left(\mathbf{s}^{-1}\right)^{*}$ & $\boldsymbol{K}_{M}(\boldsymbol{\mu M})^{*}$ & $\begin{array}{c}\boldsymbol{k}_{\text {cat }} / \boldsymbol{K}_{\boldsymbol{M}} \\
\left(\mathbf{M}^{-1} \cdot \mathbf{s}^{-1}\right)\end{array}$ & $\begin{array}{c}\text { Rate with } 100 \mu \mathrm{M} \\
\boldsymbol{p} \text {-benzoquinone } \\
\left(\mathbf{s}^{-1}\right)^{* *}\end{array}$ \\
\hline WT NfsA_Ec & $0.89 \pm 0.03$ & $1040 \pm 100$ & $860 \pm 90$ & $9.0 \pm 0.5$ \\
+R2225V & $0.96 \pm 0.04$ & $690 \pm 80$ & $1400 \pm 170$ & $1.0 \pm 0.1$ \\
+S41Y & $0.15 \pm 0.003$ & $140 \pm 10$ & $1090 \pm 110$ & N.D..$^{* *}$ \\
+T219Y & $0.29 \pm 0.02$ & $200 \pm 50$ & $1400 \pm 350$ & N.D..$^{* * *}$ \\
+F227G & $0.21 \pm 0.006$ & $200 \pm 20$ & $1040 \pm 110$ & N.D..$^{* * *}$ \\
+S224R & $0.33 \pm 0.008$ & $160 \pm 10$ & $2020 \pm 115$ & N.D..$^{* * *}$ \\
+H215C & $0.18 \pm 0.007$ & $110 \pm 20$ & $1600 \pm 240$ & N.D.*** \\
+K222V & $0.14 \pm 0.004$ & $130 \pm 20$ & $1100 \pm 150$ & N.D..$^{* * *}$ \\
\hline
\end{tabular}

\begin{tabular}{rcccc}
\hline B 20_39 & $\boldsymbol{k}_{\text {cat }}\left(\mathbf{s}^{-1}\right)^{*}$ & $\boldsymbol{K}_{\boldsymbol{M}}(\boldsymbol{\mu M})^{*}$ & $\begin{array}{c}\boldsymbol{k}_{\text {cat }} / \boldsymbol{K}_{\boldsymbol{M}} \\
\left(\mathbf{M}^{-1} \cdot \mathbf{s}^{-1)}\right.\end{array}$ & $\begin{array}{c}\text { Rate with 100 } \mu \mathrm{M} \\
\boldsymbol{p} \text {-benzoquinone } \\
\left(\mathbf{s}^{-1}\right)^{* *}\end{array}$ \\
\hline WT NfsA_Ec & $0.89 \pm 0.3$ & $1040 \pm 100$ & $860 \pm 90$ & $9.0 \pm 0.5$ \\
+R225D & $0.71 \pm 0.04$ & $450 \pm 70$ & $1600 \pm 260$ & $0.3 \pm 0.06$ \\
+S41Y & $0.12 \pm 0.006$ & $140 \pm 30$ & $840 \pm 200$ & N.D.*** \\
+F227H & $0.13 \pm 0.004$ & $320 \pm 30$ & $420 \pm 40$ & N.D..$^{* * *}$ \\
+T219Y & $0.27 \pm 0.009$ & $180 \pm 20$ & $1600 \pm 180$ & N.D.*** \\
+H215N & $0.20 \pm 0.006$ & $90 \pm 10$ & $2300 \pm 350$ & N.D..$^{* * *}$ \\
+K222R & $0.19 \pm 0.009$ & $240 \pm 40$ & $790 \pm 120$ & N.D.*** \\
+S224Y & $0.16 \pm 0.004$ & $80 \pm 10$ & $1900 \pm 240$ & N.D. ${ }^{* * *}$ \\
\hline
\end{tabular}

Supplementary Table S1: Kinetic parameters of chloramphenicol and 1,4-benzoquinone reduction for intermediates from the most plausible trajectories for (A) 36_37 and (B) 20_39. Apparent $K_{M}$ and $k_{\text {cat }}$ were calculated using Graphpad 8.0. Kinetic parameters could not be accurately determined for 1,4-benzoquinone, therefore the catalytic rate of 1,4-benzoquinone reduction was measured at a single high concentration of 1,4benzoquinone $(100 \mu \mathrm{M})$ with reactions initiated by addition of $250 \mu \mathrm{M}$ NADPH. All reactions were measured in triplicate and errors are \pm 1 S.D. In the left-most column, the terminology "+" refers to an enzyme variant that has the same amino acid sequence as the variant in the row above, plus the one additional substitution indicated. For example, "+R225V" describes a variant sharing an identical primary sequence to NfsA, with the additional substitution R225V. *Apparent $k_{c a t}$ and $K_{M}$ as determined at $250 \mu \mathrm{M} \mathrm{NADPH}$. **Measured rates following addition of $250 \mu \mathrm{M}$ NADPH. $* * * N . D .=$ not detectable (change in $\mathrm{OD}_{340}<0.1 \mathrm{~s}^{-1}$ ).

\begin{tabular}{|c|l|c|}
\hline & Average mean fold improvement of: & Average \pm SD \\
\hline \multirow{2}{*}{\begin{tabular}{c} 
Intermediates \\
\cline { 2 - 3 }
\end{tabular}} & All variants & $2.8 \pm 2.4$ \\
\cline { 2 - 3 } & Variants retaining R225 & $1.1 \pm 0.6$ \\
\cline { 2 - 3 } $20 \_39$ & Variants containing R225V substitutions & $4.5 \pm 2.2$ \\
\cline { 2 - 3 } Intermediates & All variants & $2.2 \pm 2.2$ \\
\cline { 2 - 3 } & Variants retaining R225 & $0.9 \pm 0.2$ \\
\cline { 2 - 3 } & Variants containing R225D substitutions & $3.6 \pm 2.4$ \\
\hline
\end{tabular}

Supplementary Table S2: Average mean fold improvement for all NfsA_Ec variants that either retained R225 or contained a R225V/D substitution. To calculate the average fold improvement of variants retaining R225, the fold improvement relative to wild type NfsA_Ec of all 64 variants retaining R225 was averaged. To calculate the average fold improvement of variants with the R225V or R225D substitutions, the fold improvement relative to wild type NfsA_Ec off all 64 variants containing either R225V (in 36_37 intermediates) or R225D (in 20_39 intermediates) was averaged. 